\title{
4A "ENFERMEDAD QUE MUDA DE MATICES". CARACTERIZACIÓN DEL MAL DEL PINTO EN CHIAPAS, SIGLO XVIII
}

\section{Mario Humberto Ruz} Centro de Estudios Mayas, UNAM

Dolores ARAmoni Calderón Centro de Estudios Indígenas, UNACH

El 7 de septiembre de 1798, el obispo de Chiapa y Soconusco, doctor Fermín Joseph Fuero, preocupado por la extensión y gravedad que alcanzaba en su diócesis una enfermedad que, según sus propias palabras, "con suma impropiedad denominan allí tiña... pareciendo más bien una especie rara de lepra", y aprovechando el paso por Ciudad Real del famoso naturalista José Moziño, ${ }^{1}$ solicitó del virrey Miguel Joseph Azanza y del presidente de la Audiencia de Guatemala, Don José Domas y Valle, los permisos respectivos para poder detener al médico Moziño en su diócesis y crear un hospital provisional en las salas de su propia casa, buscando facilitar el estudio de algunos afectados y "entablar un método curativo en consecuencia... para que después se curen todos con arreglo a él".

1 Nacido al parecer en Temascaltepec, destacó como estudiante en la Universidad de México, el Seminario Tridentino y la Real Academia de San Carlos. "Gozando muy buenos créditos en la práctica de la medicina", fue nombrado por el virrey de México, conde de Revillagigedo, miembro de la expedición botánica que ordenó Carlos III sc hiciese en la Nueva España, y que llegó hasta el actual Canadá (Orozco y Berra, 1854:582ss). A solicitud del jefe de la expedición, Martín de Sessé, el marqués de Branciforte concedió en noviembre de 1794 el permiso para extender la investigación al "retifilísimo Reino de Guatemala" (Taracena, 1983:25) ; allí se encontraría Moziño cuando el obispo de Chiapas implorara su auxilio, según Orozco y Berra por el temor de los prelados de contagiarse mientras administraban el óleo de confirmación (ibid.); ningún documento avala tal hipótesis. 
Al mismo tiempo, procedió a enviar una cordillera, es decir una circular, a todos los curas del obispado, ordenando realizaran una investigación exhaustiva en sus jurisdicciones sobre "el número, calidad y sexo de los contagiados", el tipo de "tiña" que manifestaban clínicamente (según la clasificación popular por "colores"), la etiología supuesta, la historia epidemiológica del padecimiento y la terapéutica o terapéuticas empleadas; datos que se reportarían según un formato anexo.

Si bien ni la acción del obispo ni la estancia de Moziño podían pasar inadvertidas para los historiadores locales o los especialistas, quienes han dedicado diversas notas a sus consecuencias, ${ }^{2}$ nadie ha estudiado hasta hoy la información que sustenta el hecho; así, la rica mina que representan los documentos enviados por los sacerdotes como respuesta a la solicitud de su pastor, ha permanecido inaccesible para los estudiosos de la medicina en nuestro país. Tales documentos, contenidos en su totalidad en un expediente guardado en el Archivo Histórico Diocesano de San Cristóbal, ${ }^{3}$ sustentan este trabajo.

Presentados a la manera de una descripción clínica tradicional, los datos han sido desglosados en cinco apartados; epidemiología, etiología, clínica, diagnóstico y terapéutica, que se ven precedidos y/o acompañados de notas históricas -impresas o documentalesmapas y cuadros, cuyo fin es proporcionar al lector un marco de referencia global para la mejor comprensión del fenómeno.

La información, como podrá verse, cubre casi todos los pueblos mayores del obispado (la excepción serían los de la provincia de Llanos, representada apenas por Socoltenango, Soyatitán y San Bartolomé) y en ella se dan cita las opiniones más dispares: desde apreciaciones realmente "científicas" - como las de los curas de Tonalá e Ixtapa o el de Totolapa, amigo de célebres médicos de la época como él mismo declara- hasta aquellas que repiten tan sólo creencias populares; éste es pues otro buen ejemplo del mosaico cultural que siempre ha sido Chiapas.

2 Cf., entre otros, Nazar Cal y Mayor (1962), Taracena Arreola (1983) y Boletin del Archivo General de Chiapas (1983).

3 " Año de 1798. El ilustrísimo señor doctor don Fermín Joseph Fuero, del Consejo de su majestad, dignísimo obispo de Chiapa, etcétera, sobre la curación de la especie de lepra vulgarmente nombrada tiña, Secretaría de Go bierno". AHD, sin clasificación. Cien fojas. 


\section{Antecedentes}

-Notas médicas 4

El Mal del Pinto es una treponematosis con manifestaciones únicamente cutáneas, de tipo crónico y benigno, que se caracteriza por alteraciones pigmentarias. Originaria del continente americano y localizada sobre todo en las regiones tropicales, ${ }^{5}$ es producida -como su nombre lo indica- por un treponema, el herrejomi o carateum, tan parecido al que produce la sífilis (Treponema pallidum) que son morfológicamente indiferenciables.

Es importante destacar que el agente se identificó hace menos de cincuenta años (por José Alfonso-Armenteros, en Cuba) aunque su existencia fue prevista desde 1927 por el mexicano Salvador González Herrejón, en cuyo honor recibió su denominación.

La transmisión se realiza por contacto directo de piel afectada con sana y, supuestamente, por alguna solución de continuidad. Tomando en cuenta sus características epidemiológicas se presume que puede ser transmitido por insectos, pero esto no ha podido ser demostrado. No existe transmisión placentaria ni por contacto sexual.

Una vez inoculado, el treponema sigue un período de incubación entre 7 y 20 días (en casos extremos 60), apareciendo luego la lesión inicial llamada chancro pintoso, que en ocasiones se mezcla con las lesiones de diseminación o píntides, popularmente conocidas por "jiotes" o "empeines": placas eritematoescamosas de número y tamaño variables, diseminadas en forma irregular y asimétrica en miembros, tronco y cara, respetando pliegues y genitales. $\mathrm{Al}$ desaparecer pueden dejar manchas hipo o acrómicas.

La evolución de las píntides da origen a lesiones tardías discrómicas que pueden estar localizadas (sobre todo en partes salientes como codos, rodillas, tobillos, manos, pies, muñecas) o diseminadas en cara y tronco. De una simetría marcada, combinan alteraciones pigmentarias y vasculares, dan lugar a diferentes tonos que las califican: pinto azul, blanco, café, amarillo o rojo, siendo lo más común el que se presenten juntas manchas acrómi-

4 Este apretado resumen se basa primordialmente en Saúl (1977:193-197).

5 En México se calcula que afecta a medio millón de personas a lo largo de doce estados, localizándose los sitios principales en las márgenes del Balsas, Grijalva y Usumacinta (Saúl, ołp. cit.:913). A decir de Nazar (op. cit.: 12) en 1962, el padecimiento afectaba a los "habitantes del $22 \%$ del territorio" de Chiapas. 
cas e hipercrómicas. "En las personas de piel oscura predomina la pigmentación; en las de piel blanca... el eritema, de ahí la policromía de esta enfermedad" (Saul, op. cit.: 195).

\section{-Notas históricas}

La acción emprendida por el ex-rector de la Universidad de México y desde 1796 obispo de Chiapa y Soconusco, Fermín José Fuero, contra la enfermedad de sus feligreses, se inició el 27 de agosto de 1798, fecha en que proclamó un edicto con el que buscaba "atinar con la raíz" del padecimiento a través de un "maduro examen... para averiguar sus efectos políticos, ya que [aducía] nuestros conocimientos no alcanzan a la total investigación de los físicos".

Los motivos de su interés se transparentan en el propio edicto, cuando señala que

El contagio va a más cada día, y debemos temer que dentro de pocos años no se encuentre persona libre de él. La falta de médicos que absolutamente padecen $\mathrm{y}$ han padecido estas provincias puede haber sido, y con gran efecto sería el motivo de no haberse sofocado tan terrible monstruo en su nacimiento, de que con el tiempo haya adquirido más fuerzas y extendida por consiguiente sus estragos. Por lo menos no tenemos hasta ahora noticia de que se haya pretendido exterminar por aquellos medios que sugiere la prudencia científica en tales casos.

La enfermedad, que a su juicio hacía "con menos estruendo mayor daño a la población de la América que las viruelas", se le antojaba responsable, con mucho, del

decremento sensible de la población de estos países, y porque unos padres enfermizos, o se han hecho estériles del todo o sólo han procreado unos hijos de una constitución más viciada y más debil, de poca aptitud para el trabajo y casi ninguna esperanza para llegar a [1a] longevidad.

A causa de ello "La Religión se va quedando sin prosélitos, el Estado sin vasallos y estos feracísimos campos sin cultivadores y sin habitantes". Así, concluye, "no hay cosa pues que no nos excite y compela en cierto modo a procurar el remedio de tanto mal; tratamos la causa de Dios, la del rey, la de la Patria y la de nosotros mismos".

La presencia de José Mariano Moziño, a quien conocía de mu- 
cho tiempo atrás, se le antojó la oportunidad ideal para "hacer un singular beneficio" a la zona aprovechando "su pericia en la medicina, su desinterés, su celo por el bien común y sus sentimientos de humanidad", Por ello se apresuró a escribir al virrey de la Nueva España y al presidente de Guatemala, pidiéndoles concedieran licencia al naturalista para quedar en Chiapas, "nada más que el tiempo preciso a entablar un método curativo en consecuencia de las observaciones que haga con los mismos enfermos, para que después se curen todos con arreglo a él".

Los pacientes serían alojados en las salas de su reducida casa, ${ }^{6}$ convertida en hospital, y a su cargo quedaría suministrar a quienes "quieran disfrutarlos, los alimentos y medicinas que necesiten... pues por redimirlos de $\tan$ asqueroso contagio gastaremos con el mayor regocijo no sólo las pequeñas rentas de nuestra dignidad, sino todos los demás bienes adquiridos antes de nuestra exaltación a ella". A los fieles que se prestaran a auxiliar a los eventuales internos se les concederían cuarenta días de indulgencia por cada obra de piedad que hicieran, "entendiéndose que reputamos por tal hasta la material de servirles una taza de caldo", pues, sentencia, "los más menesterosos son los más acreedores a nuestra liberalidad, y siendo tan loable el ejercicio general de esta virtud, lo es inconcusamente más cuando se emplea en los pobres indios, entre los cuales apenas hay alguno que no sea muy desvalido". En caso de que algunos de los afectados encontraran alojo en las viviendas de la ciudad, Moziño pasaría a visitarlos en ellas.

El objeto del edicto no era tan sólo mover a los fieles a usar de la caridad cristiana para con los enfermos, sino que buscaba al mismo tiempo informar a los curas del obispado, de su obligación de formar "una lista del número de enfermos de esta clase que hubiere en sus feligresías, con expresión de sexos y calidades", para que -una vez en poder de la Secretaría de Cámara y Gobierno de la mitra- se analizaran las necesidades económicas. Asimismo, quedaría a cargo de los sacerdotes el convencer a algunos de sus feligreses enfermos a concurrir al hospital.

El edicto, en forma de circular, se turnó a las diversas provincias del obispado (mapa 1) acompañado de un machote que los curas deberían llenar señalando cuántos españoles, indios y ladi-

6 El palacio episcopal se hallaba por entonces derruido. 
nos -separando hombres y mujeres- se hallaban afectados por las tres clases de "tiña": blanca, negra y encarnada.

Si bien la carta al presidente de la Audiencia, pidiendo apoyara sus esfuerzos, no proporciona más datos de los ya señalados, la que dirigiera Fuero al virrey el 7 de septiembre solicitando su permiso para retener a Moziño en Chiapas, aun en detrimento de la expedición científica, contiene un párrafo con el que el obispo busca apoyar su petición, que nos parece vale la pena reproducir:

No me persuado que sea de más importancia la utilísima ocupación de inspeccionar a la naturaleza, que la de redimir a nuestros hermanos de un achaque que les quita el mayor bien temporal, que es la salud, y agregar al Estado las infinitas generaciones que, según mi opinión, le está defraudando esta lepra.

El virrey respondió al obispo el 26 de septiembre que tras consultar con don Martín de Sessé, director general de la expedición, ${ }^{7}$ se autorizaba a Moziño una licencia de dos meses a partir del primero de octubre y no más, pues los científicos deberían regresar a España en la primavera de 1799.

El 7 de noviembre el diocesano enviaba nueva carta al virrey dando cuenta de los escasos avances logrados: los pacientes que se presentaron fueron pocos ("todos quieren ver en cabeza ajena las experiencias") ${ }^{8}$ y la enfermedad se había mostrado mucho más rebelde de lo previsto, sobre todo la variedad blanca. La próxima partida de Moziño le provoca gran desconsuelo pues traer a otro médico desde México resulta impensable dados los altos costos que presupondría, mientras que con el naturalista, quien "hace de médico, de boticario y hasta de cocinero de los enfermos", los gastos son mínimos.

Además de sus labores como médico, Moziño había iniciado el

7 Debe señalarse que en su respuesta al virrey, dada el 26 de septiembre, Sessé mostraba su inconformidad con la actitud de Moziño al dar lugar al obispo para contar con él, pues la expedición llevaba ya buen retraso. Asintió pues de mala gana a la solicitud, pero no dejó de insistir en que el dibujante Vicente de la Cerda debía regresar de inmediato con sus láminas y el herbario.

El pintor, calificado por el obispo como "indio cacique", salió entonces a México a pesar de los consejos del diocesano de quedar en Chiapas mientras se le calmaban las "continuas invasiones de una fiebre".

$8 \mathrm{La}$ renuncia de los pacientes a internarse había sido ya prevista por los curas de Acala, San Bartolomé y Chiapa. En ningún momento se menciona en el texto cuántos pacientes se trataban en el hospital; sólo el cura de Huehuetán señaló haber enviado cuatro. 
examen de un lote de tierra enviado por el cura de Ocozocuautla, cuyo contenido en azogue se presumía ser "tanto o más rico que el de Almadin y Guancavelica".?

La carta contiene asimismo dos sentidos párrafos sobre el obispado, que dan buena cuenta tanto de su precaria situación, como de la sensibilidad de su pastor

porque todo falta en este país infeliz, que no podrá ver un alma sensible sin enternecerse extremadamente. Nuestros hermanos, Señor Excelentísimo, en ninguna parte viven con mayor miseria; en ninguna se encuentra más degradada la especie humana. No hiperbolizo, Señor, ni quisiera que Vuestra Excelencia llegara a presumir que el clima de Chiapa inspira a sus obispos unos genios melancólicos y ponderativos.

Día con día estoy exprimentando unas calamidades de todos genéros en mis feligreses, que parecerán increíbles al que las sepa de lejos. Unas tierras feracisimas, en que el Criador proporcionó al hombre no sólo lo bastante para sus necesidades, sino también para sus delicias, están despobladas, y los pocos habitantes que hay en ellas están enfermos y no hay quien los cure; desnudos y sin tener quien los vista; hambrientos y... permitame vuestra Excelencia suspender aquí una lastimosa narración, porque no quiero llenar el sensible ánimo de Vuestra Excelencia de la insoportable amargura del mío.

Tal como lo previera ya el obispo en una segunda carta al presidente de la Audiencia (7-XI-1798), donde señalaba temer que no tuvieran "cumplido efecto" sus intenciones, "porque en pocos días es preciso hacer muy poco, y no hay arbitrio de variar los métodos, por la falta de tiempo y de sujetos que quieran someterse a ellos", poco fue lo logrado por Moziño. Así en su tercera y última carta al virrey, fechada el doce de diciembre, Fuero anota

Regresa para esa corte don José Mariano Moziño, dejándome con el desconsuelo de no haber podido lograr la curación completa de alguno o alguno de los inficionados, sin embargo de que en cinco de ellos hay indicios manifiestos de estar próxima a conseguirse.

Ya veo, el mismo Moziño me lo ha repetido innumerables veces, que las enfermedades rebeldes - especialmente cutáneas- suelen no ceder sino al cabo de muchos meses, y eso cuando se tiene la fortuna de atinar con el verdadero método. El tiempo que a este profesor ha concedido vuestra excelencia ha sido muy corto para una empresa que tal vez no se conseguiria en años enteros.

9 A decir de Taracena (op. cit.:58) se comprobó que el mineral (en el que el obispo cifraba grandes esperanzas para el desarrollo de la provincia) no era de calidad por carecer de cinibrio. 
Moziño también escribió al presidente de la Audiencia (26 de noviembre), dando cuenta del fracaso. A pesar de todo su empeño, las especies de "vitiligo" se mostraron rebeldes al tratamiento; más la blanca (tratada con fricciones mercuriales e ingestión de antimonio crudo) que la negra, que cedió un poco a las fricciones. ${ }^{10}$ Prometía, empero, proponer nuevos métodos antes de salir de la Audiencia; ignoramos si lo hizo.

El científico abandonó Chiapas en el tiempo previsto, trasiadándose a España en 1803; el obispo Fuero moriría en su diócesis el 14 de junio de 1800 . Once años más tarde, los protomédicos de la Audiencia realizaban un nuevo esfuerzo por erradicar el Pinto, que se extendía ya hasta Yucatán, Honduras y La Habana."

La enfermedad, calificada en 1811 por don Antonio María de Berecochea como "tan antigua como la lengua chiapaneca, aunque en el día más general", 12 sería sometida a un riguroso cotejo científico para diferenciarla del liquen "o sérpigo", del empeine negro "o psira", de la "elefantiasis de los árabes" y del herpes "o donwisorm flamenco"; la etiología supuesta vería invocar otra vez desde cambios humorales, "aires ambientes particulares" que alteraban a las glándulas sebaceas, virus, ectoparásitos, mala calidad de las aguas y picaduras de mosquitos, hasta la ingestión de chaya, langostas, pulgas, hormigas y piojos; desfilarían nuevas y viejas terapéuticas: jarabe de malsabsia, diacodio, baños en temascal, aguas de cal mercurial con fagedérnica o lejía fuerte de potasa, "piedra infernal" para tocar las manchas, o aceite esupireumático de la leña. No obstante todo ello, la "enfermedad que muda de matices" - según la llamara el Protomedicato- no dejaría de estigmatizar a los chiapanecos hasta el advenimiento de la penicilina.

10 En la Gaceta de Guatemala del primero de octubre se consigna que, además de tratar a los enfermos, Moziño recomendó que, para evitar contagios, "sólo ocuparan las camas de noche; en el día pasearan, se bañaran y dejaran ventilar las camas". Asimismo se mencionaba que el naturalista consideraba como una misma enfermedad a "la tiña de Teguantepeque,... la lepra de Chiapa y [la] tinigua de la provincia de Mechoacán" (en Taracena, op. cit.: 57-58).

11 Tal mencionaban, en 1800, el fiscal de la Audiencia a cuyo juicio el mal se había extendido de un radio de veinte a ciento cincuenta leguas en tan sólo 20 años (Vid Ruz, "El hospital del común de pobres...") y, en 1813, el informe del Protomedicato tantas veces citado.

12 Este y los siguientes datos constan en los textos presentados por Nazar (op. cit.). 


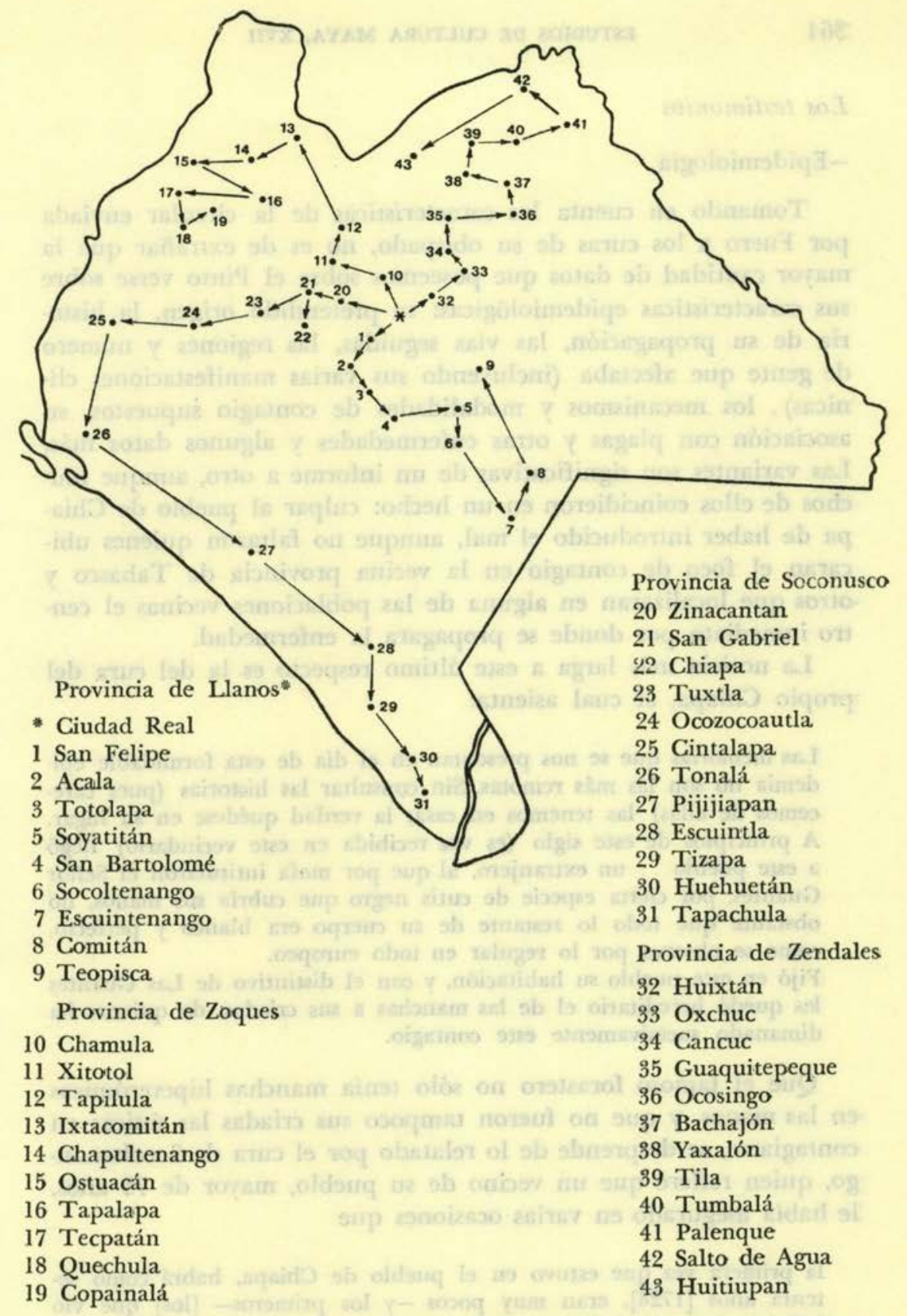

- Nota: se ha respetado el criterio de "provincias que señalan las cordilleras, aunque éstas no correspondan con exactitud a las provincias del Chiapas colonial, ni geográfica ni administrativamente.

Mapa 1. Rutas de correos (cordilleras). 


\section{Los testimonios}

\section{-Epidemiología}

Tomando en cuenta las características de la circular enviada por Fuero a los curas de su obispado, no es de extrañar que la mayor cantidad de datos que poseemos sobre el Pinto verse sobre sus características epidemiológicas: su pretendido origen, la historia de su propagación, las vías seguidas, las regiones y número de gente que afectaba (incluyendo sus varias manifestaciones clinicas), los mecanismos y modalidades de contagio supuestos, su asociación con plagas y otras enfermedades y algunos datos más. Las variantes son significativas de un informe a otro, aunque muchos de ellos coincidieron en un hecho: culpar al pueblo de Chiapa de haber introducido el mal, aunque no faltaron quienes ubicaran el foco de contagio en la vecina provincia de Tabasco y otros que localizaran en alguna de las poblaciones vecinas el centro inmediato por donde se propagara la enfermedad.

La noticia más larga a este último respecto es la del cura del propio Chiapa, el cual asienta:

Las memorias que se nos presentan en el día de esta formidable epidemia no son las más remotas. Sin consultar las historias (pues carecemos de ellas) las tenemos en casa; la verdad quédese en su lugar. A principios de este siglo (es voz recibida en este vecindario) llegó a este pueblo... un extranjero, al que por mofa intitularon el Señor Guantes, por cierta especie de cutis negro que cubría sus manos, no obstante que todo lo restante de su cuerpo era blanco y perfecto, como se observa por lo regular en todo europeo.

Fijó en este pueblo su habitación, y con el distintivo de Las Guantes les quedó hereditario el de las manchas a sus criadas, de quienes ha dimanado sucesivamente este contagio.

Que el famoso forastero no sólo tenía manchas hipercrómicas en las manos, y que no fueron tampoco sus criadas las únicas en contagiarse, se desprende de lo relatado por el cura de Socoltenango, quien refiere que un vecino de su pueblo, mayor de 75 años, le había asegurado en varias ocasiones que

la primera vez que estuvo en el pueblo de Chiapa, habrá como setenta años [1728], eran muy pocos $-y$ los primeros- [los] que vio inficionados con el dicho mal, y que aun conoció [a] la primera que se vio en dicho pueblo, la cual fue una india oriunda del mismo pueblo a quien llamaban por ironía La Guantes, por tener pintadas las manos. 
Y supo igualmente que la tal india contrajo dicho mal de un forastero que acaso enfermó en aquel Cabildo, porque siendo ésta curandera, la buscaron para que le curara, y - en efecto- habiéndolo practicado untándole varias veces el estómago, de aquí le resultaron las. manchas en las manos, y decían había asegurado la dicha india eran de las mismas que el tal forastero tenía en el estómago.

Como era de esperar, los primeros en verse contagiados fueron los cercanos a Chiapa. Así, un anciano de 80 años, vecino deAcala, aseguraba que "desde sus ascendientes ya había tradición" de la enfermedad; ${ }^{13}$ los de Ixtapa mencionaban que los primeros. casos se presentaron hacia 1718, y en San Gabriel cerca de 1738, y un año antes se contagiaron una o dos personas en Ostuacán,. Magdalenas y Sayula. Soyaló, por su parte, sabía de "tiñosos" desde más o menos 1760 .

Restringida en su primer momento a Chiapa y los pueblos. aledaños, ${ }^{14}$ la enfermedad habría de diseminarse "en los años de hambre causada por la langosta", cuando los habitantes de tales. pueblos se dispersaran por toda la provincia buscando regiones menos castigadas. Así, los de Tizapa acusaban a los de Chiapa y Totolapa de haber introducido el mal hacia 1770 o 1771 . La inmigración de los chiapanecas provocó asimismo un aumento notable en el número de los enfermos en Soyatitán, que antes del "tiempo de la epidemia" se "reducían a dos o tres". Los de Totolapa, sin poder identificar el foco originario de una patología que afectaba a todos sus habitantes ("no se encuentra uno quedeje de padecerla"), situaban con precisión la fecha: 1772, el año "de la peste del chapulín" que mandara Santa Ifigenia. ${ }^{15}$

Tenejapa, por su parte, sólo poseía dos afectados con "tiña negra"; gentes de Totolapa y San Lucas, quienes pasaron al pueblo tzeltal hacía "como treinta años, pequeños y ya contagiados"..

En Huehuetán se aseguraba saberse de casos de "tiña" desde hacía más de 30 años, "que con motivo de venirse a socorrer mu-

13 Sólo cincuenta de los setecientos habitantes de este pueblo estaban libres. del padecimiento.

14 Según el regidor de Ciudad Real, la enfermedad "se mantuvo estacanda . en el pueblo de Chiapa sin que hubiese pasado ni aun a los más vecinos", hasta 1769-70 (en Nazar, op. cit.: 23).

15 En realidad la plaga de langosta y la consecuente hambruna habian asolado a la provincia desde 1769 (véase el informe del Protomedicato en Nazar, op. cit.: 40-41), pero ya desde 1766 se padecian hambres en el área (vid infra, informe de Chapultenango). 
chas familias, de todas calidades, de Chiapa, Tusta y demás pueblos de Soques, infestaron toda esta provincia por venir la mayor parte contagiada". Otros cuatro chiapanecas "tiñosos" se trasladaron por las mismas fechas a Chamula, donde transmitieron la enfermedad a tres personas. En Tonalá, se supo de afectados hacia 1769 o 70, cuando pasaron a la zona "los de Chiapa".

En Tapachula y los cinco pueblos de su beneficio la enfermedad se introdujo hacia 1768, "tras radicarse en los pueblos gente de Chiapa, inmigrada por la epidemia de langosta".

Los habitantes de San Bartolomé, culpados por los tres enfermos de Oxchuc de haberles transmitido el mal hacia 1783, achacaban a su vez su propio contagio a los de Acala, de donde pasó "a poco que se establecieron los correos mensuales", pues alega. ban que el objeto transmisor había sido "la corneta que usan dichos correos, pues como quiera que el tallacán que sacaban del pueblo de Acala estaba contagiado", tal como demostraba el hecho de que el primero que se vio con el mal fue un indio, de apodo "el tiñoso", cuya desgracia fue "saber el castellano", lo que le valió ser nombrado correo. $\mathrm{Y}$ en Acala se contagió también el único vecino que padecía de pinto en San Martín.

Tuxtla, por su parte, propagó la enfermedad a Ocozocoautla en 1774, cuando llegó a éste último pueblo un vecino tuxtleco, que fue el primero que se vio allí con tales manchas.

Los de Tila no pudieron precisar la época en que se inició en el pueblo el "jiote", pero aseguraban que "la tiña" la habían importado de Tabasco "los mismos indios criollos" que "en el tiempo de hambre" pasaron a aquella provincia buscando subsanar sus necesidades. Ocosingo y Sibacá alegaban un foco doble: Tabasco y otros pueblos de Chiapas, sin poder concretar fechas, aunque situaban el inicio del mal como ocurrido en la generación de sus padres.

Los cancuqueros ignoraban fechas y origen, pero "conjeturaban" que el papel de transmisores lo jugaron sus vecinos de Guaquitepec.

Don Francisco Xavier Allanegui, beneficiado de Chapultenango, Nicapa, Tutuán y Sunuapa, olvidó preguntar de dónde creían los vecinos provenía la enfermedad, limitándose a señalar la época en que por primera vez se registró en tales poblaciones: hacia 1766, "tiempo de un hambre general que hubo", en Chapultenango; hacia 1760 en Sunuapa y desde 1740 en Nicapa y Tutuán. 
El cura de Tonalá y su valle resume las hipótesis y confusiones existentes al señalar que "el mal no es tan antiguo como se piensa", pues a decir de los ancianos "en el principio de este siglo [xvIII] era muy corto el número de tiñosos que se conocía". Algunos afirmaban, "aunque con variedad acerca del tiempo", que había sido difundido por "una mujer gálica que vino de uno de los pueblos de Tabasco al de Chiapa", lo que a su juicio es falso pues en la provincia vecina "no se conocieron las manchas de tiña hasta que los chiapanecos fueron a ella".

Otros de sus feligreses, "con más fundamento", repiten la historia del forastero "manchado" [aunque esta vez le achacan "una mano blanca'], pero también lo duda ya que "aunque es cierto que los males más extraños que se conocen entre nosotros han venido de las naciones extranjeras", las tales manchas "no creo se conocen en parte alguna de España" a pesar del activo comercio entre españoles y otras naciones; por tanto, apunta, "luego debemos convenir en que la tiña no se ha venido de los extranjeros, y que absolutamente se ignora cuál haya sido su principio en el pueblo de Chiapa, en donde se cree originada".

Si bien los testimonios coinciden en señalar a las emigraciones masivas durante los años de hambruna como responsables de una difusión acelerada del padecimiento, no puede soslayarse el papel jugado en años previos y posteriores por el comercio, que explicaría no sólo el que los pueblos comarcanos a Chiapa fueran los primeros en contagiarse, sino que la enfermedad alcanzara para 1798 regiones tan distantes como Xalapa y Tehuantepec, ${ }^{16}$ zona esta última que -a decir del obispo- estaba "contaminada en su cabecera y gran número de pueblos anexos". De allí que el cura de Chiapa postulara como "la más útil medicina" el evitar las actividades comerciales que desarrollaban los contagiados.

Factor que coadyuvaba a diseminar la enfermedad era, según el cura de Soyatitán, "la poca aprehensión" de los no afectados, quienes incluso se vestían con ropa de los enfermos; las diferencias climáticas entre un pueblo y otro, fueron alegadas por los sacerdotes de Tenejapa y Tonalá.

Según el primero, el que los "tiñosos" llegados al poblado desde Totolapa y San Lucas no hubieran contagiado ni a sus mujeres ni a sus hijos, se debía al clima excesivamente frío de Tene-

16 Tal consta en el edicto de Fuero. 
japa, "porque aseguran que en sus pueblos, que son calientes y están enteramente contaminados con esta enfermedad, el que no nace con ellas, a poco tiempo se le advierten las manchas".

El de Tonalá atribuía la mayor frecuencia del padecimiento en pueblos de "temperamento" caliente, al hecho de "mantenerse sus habitantes sudando el día y la noche".

Otro factor coadyuvante, la falta de médicos que se hubieran avocado a descubrir una terapéutica efectiva, había sido señalada por el obispo ya desde su edicto.

No escapó a algunos curas observadores el hecho de que la cohabitación con un enfermo, incluso la sexual, no implicaba necesariamente contagio; así lo reportaron los de Soyatitán, Chamula, Tenejapa, Tonalá y Chiapa. El de Tonalá, por ejemplo, anota que podía presentarla la mujer y no el marido, o estar enfermos ambos padres sin que lo estuvieran los hijos. "sin embargo de que se servían de unos mismos muebles, dormían en una misma cama y se cubrían con la misma ropa", El de Chiapa, por su parte, destacó que no presentaban manchas los recién nacidos, ni las adquirían los niños antes de los seis o siete años, en lo que coincidió el de Ixtapa, empleando el argumento para apoyar su hipótesis sobre una ectoparasitosis. A favor de un contagio prenatal y en la edad pre-escolar, como hemos visto, se manifestó el cura de Tenejapa.

El cura de Soyatitán, Vicente Ramón de Rivera, agregó a su reporte un dato interesante: "en las viruelas pasadas próximamente [¿1779?], y en las anteriores, sanaron muchos, pero pasados algunos meses les volvió el contagio".

Uno de los objetivos prioritarios del obispo al solicitar la colaboración de sus párrocos había sido el enterarse del número de enfermos, sus "calidades" raciales y el tipo de "tiña" que presentaban. Con sus respuestas hemos integrado los cuadros y gráficos que continúan, buscando facilitar su manejo, y dejando algunas consideraciones para la recapitulación final. 


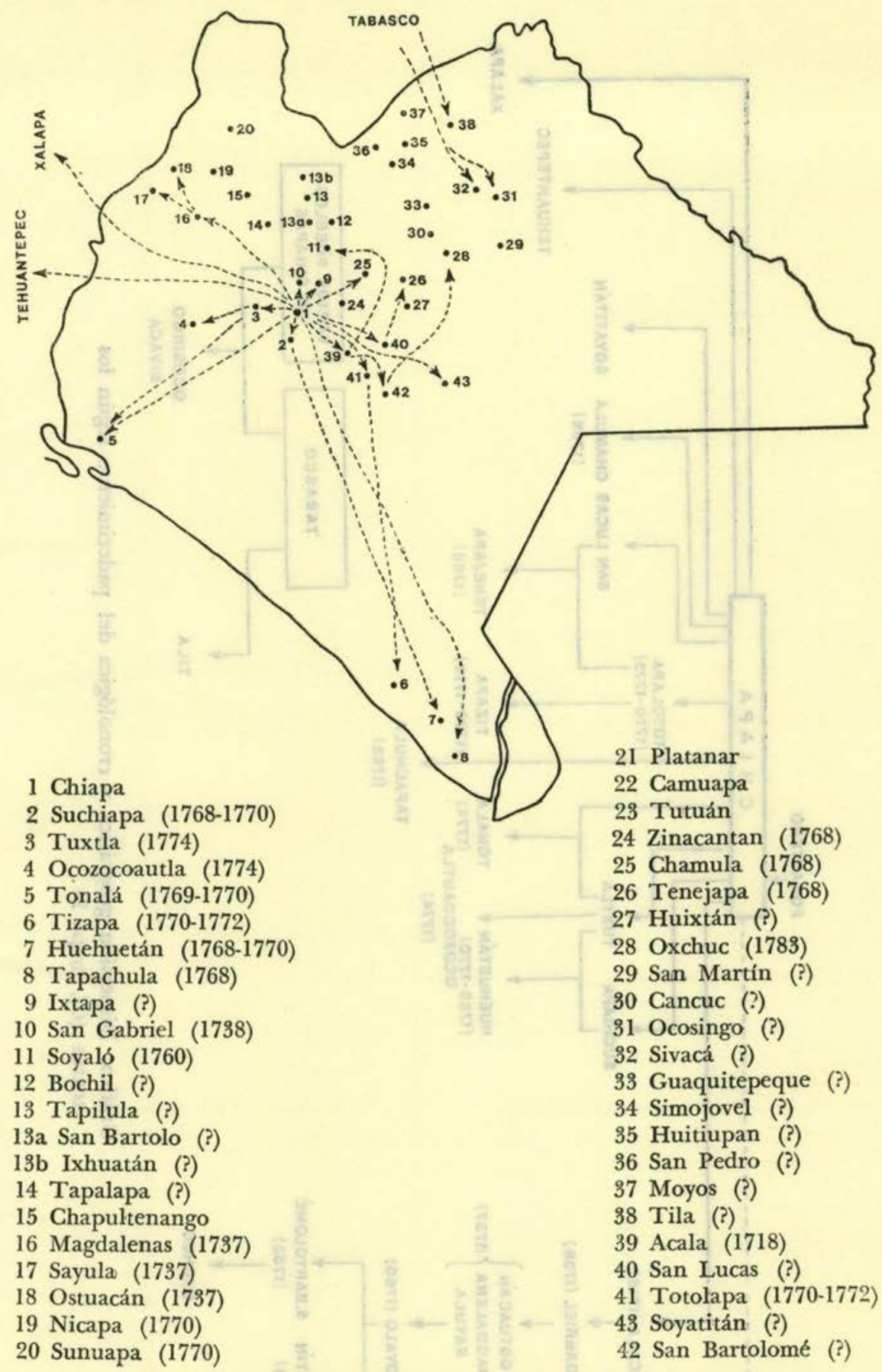

Mapa 2. Propagación de la enfermedad y año en que se registró ( $C f$. Gráfico). 


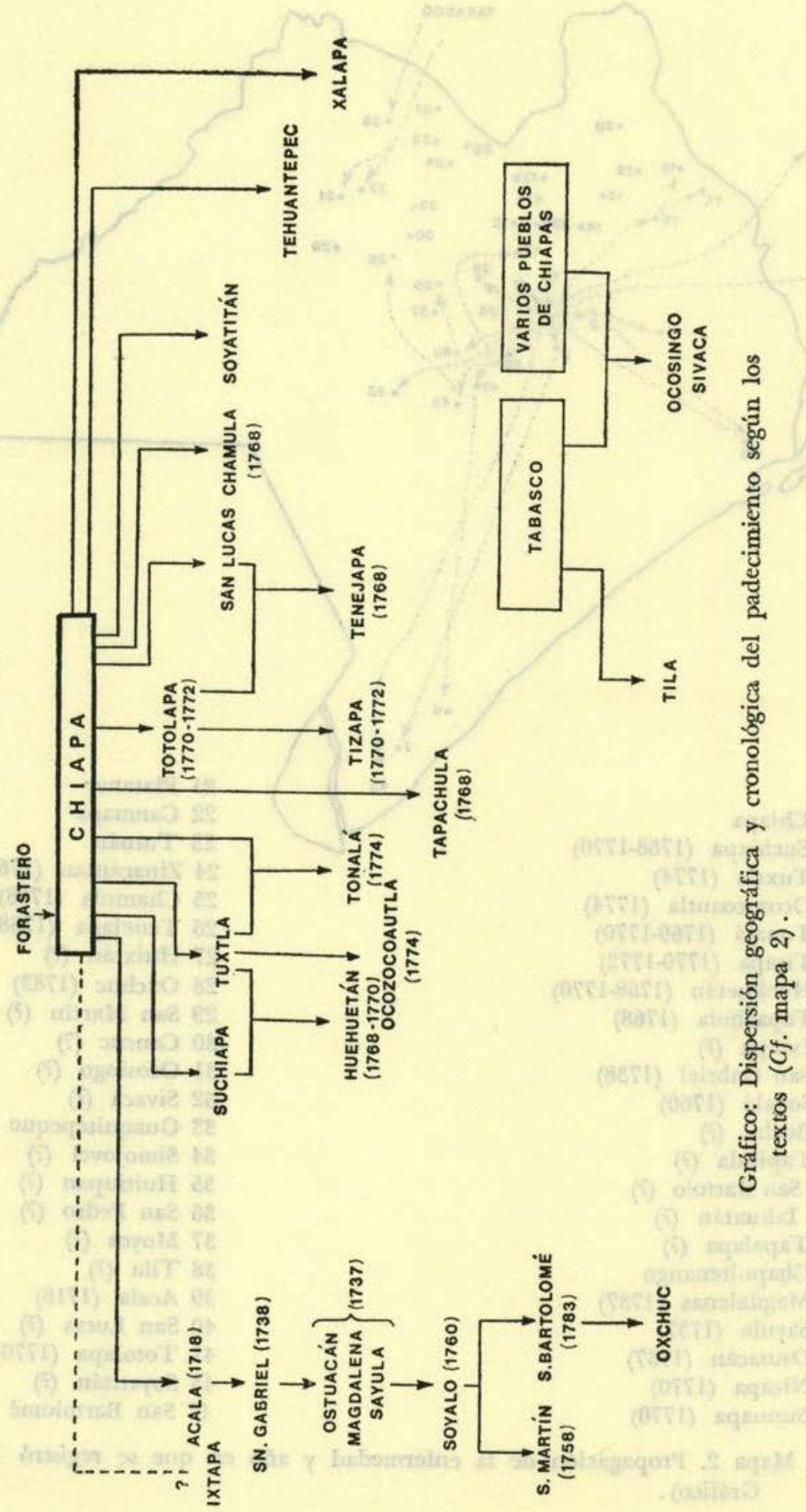

Estudios de Cultura Maya. Vol. XVII, 1988

Instituto de Investigaciones Filológicas/

Centro de Estudios Mayas, UNAM 


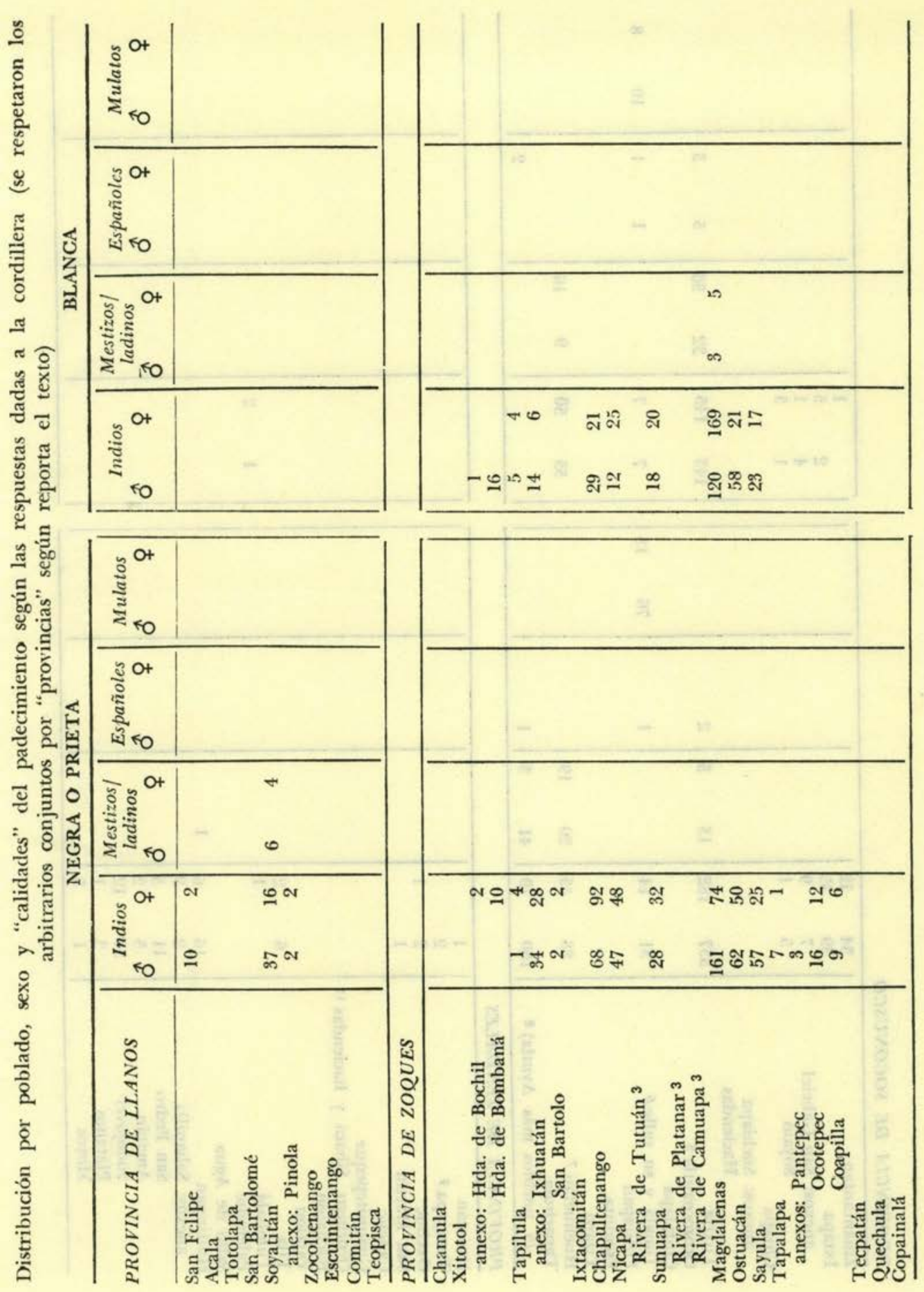



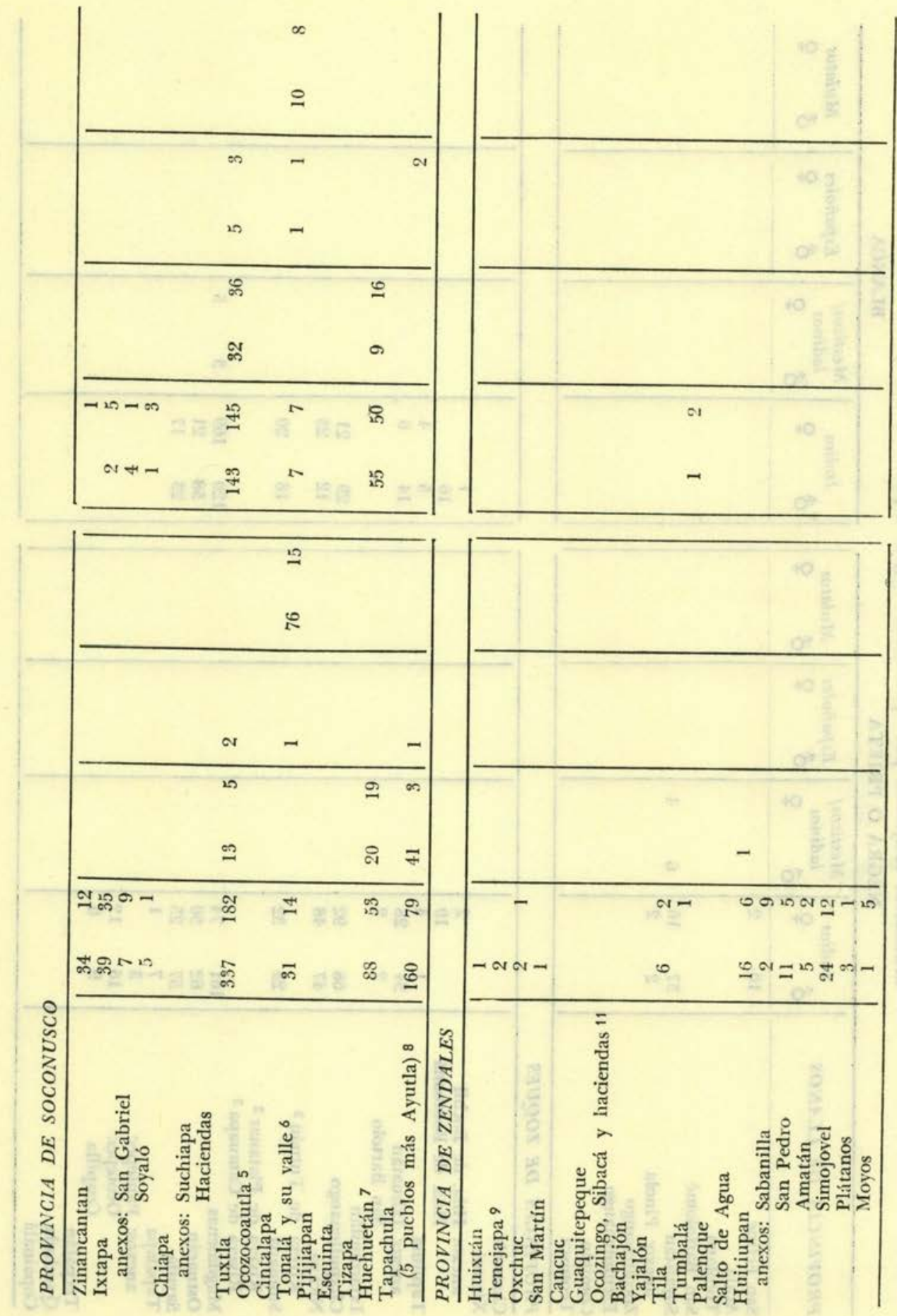

Estudios de Cultura Maya. Vol. XVII, 1988

Instituto de Investigaciones Filológicas/

Centro de Estudios Mayas, UNAM 

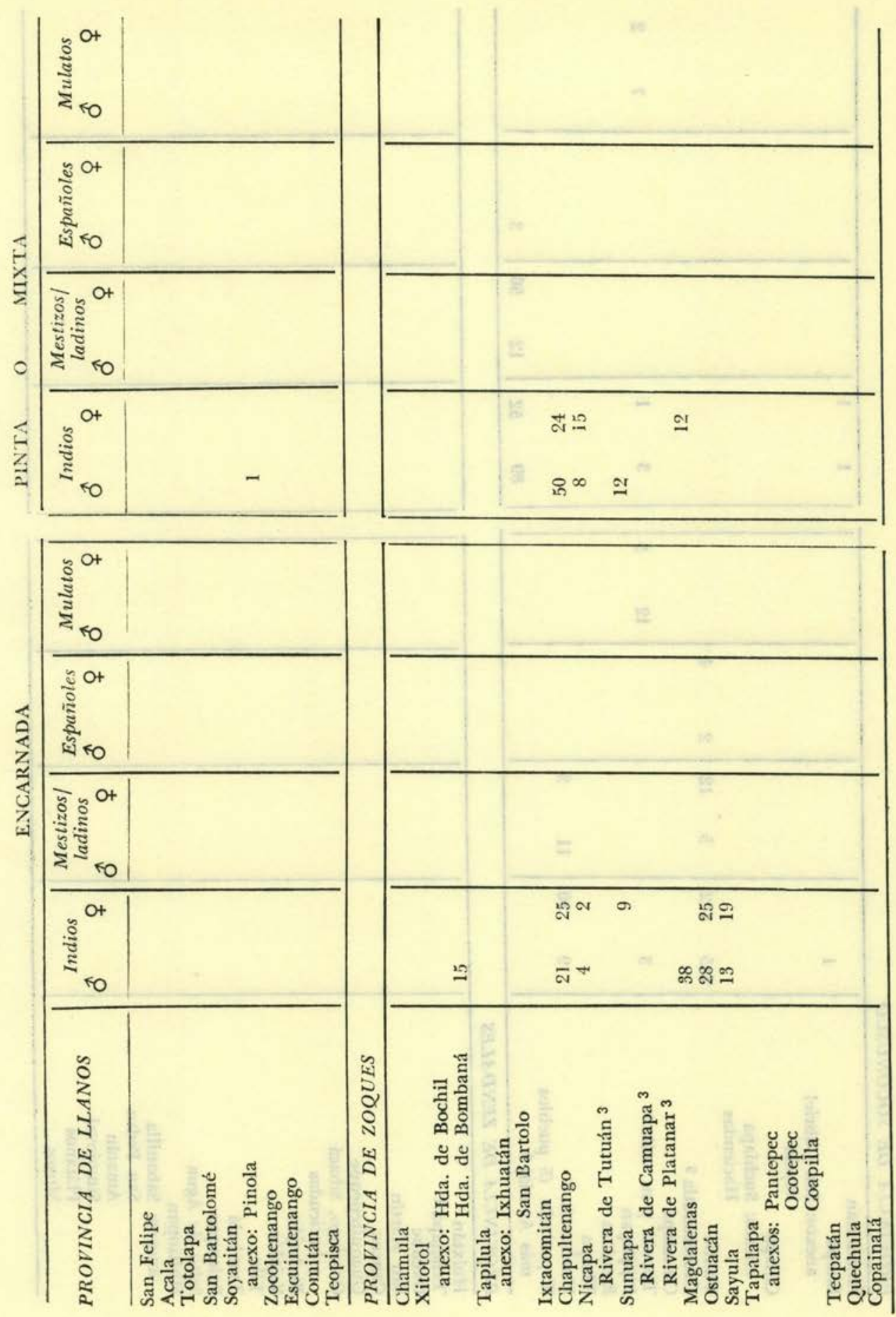


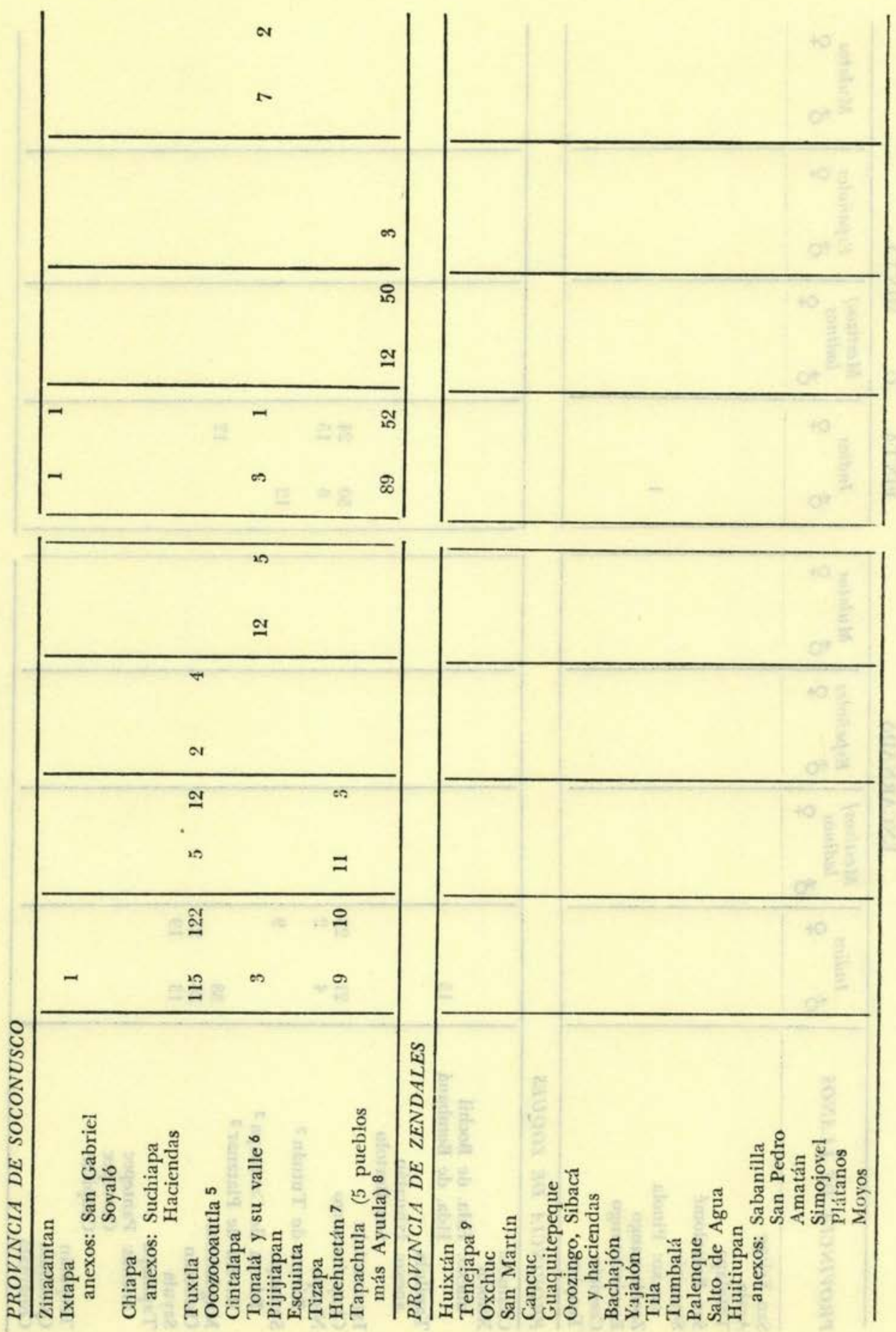

Estudios de Cultura Maya. Vol. XVII, 1988

Instituto de Investigaciones Filológicas/

Centro de Estudios Mayas, UNAM 

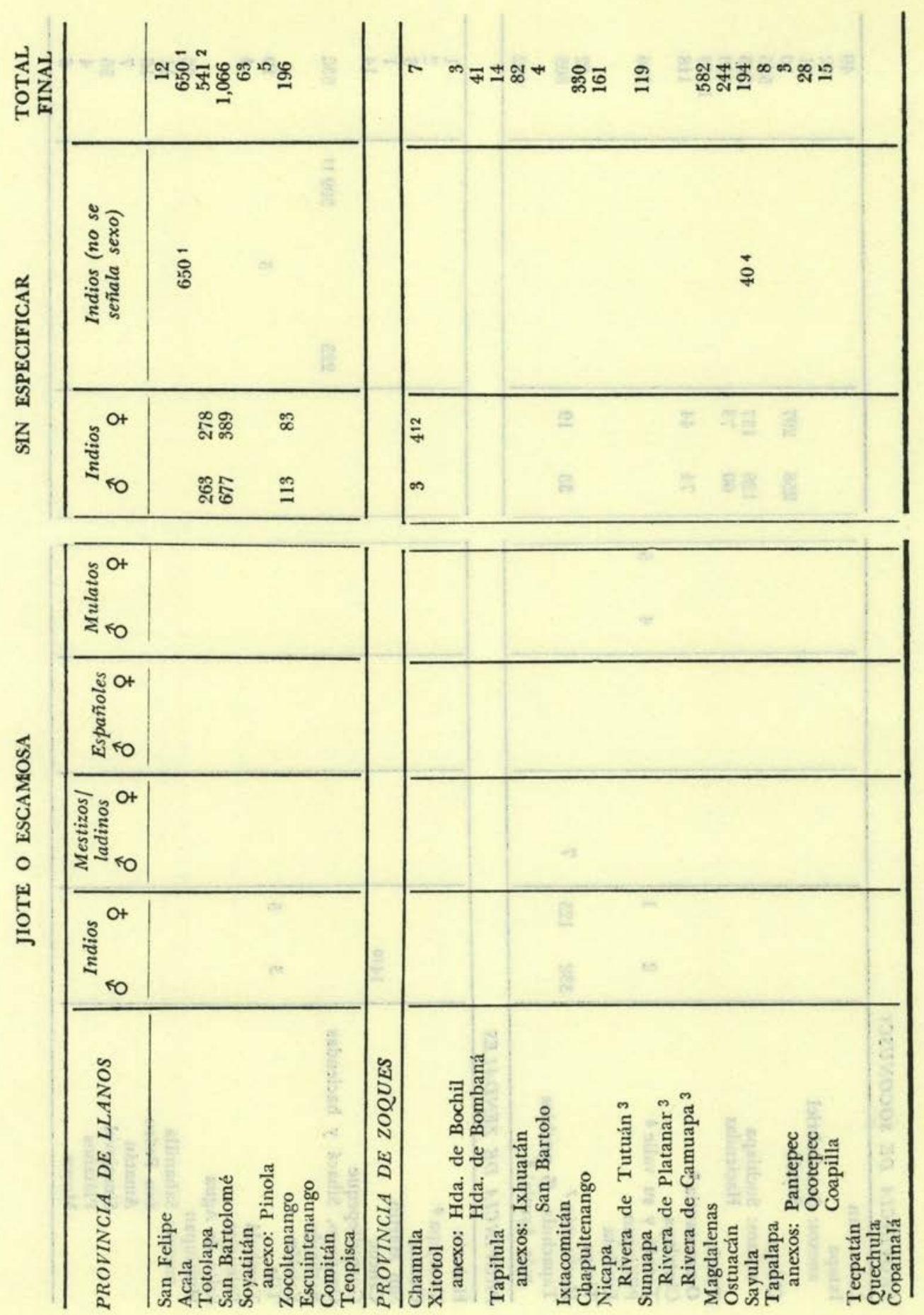


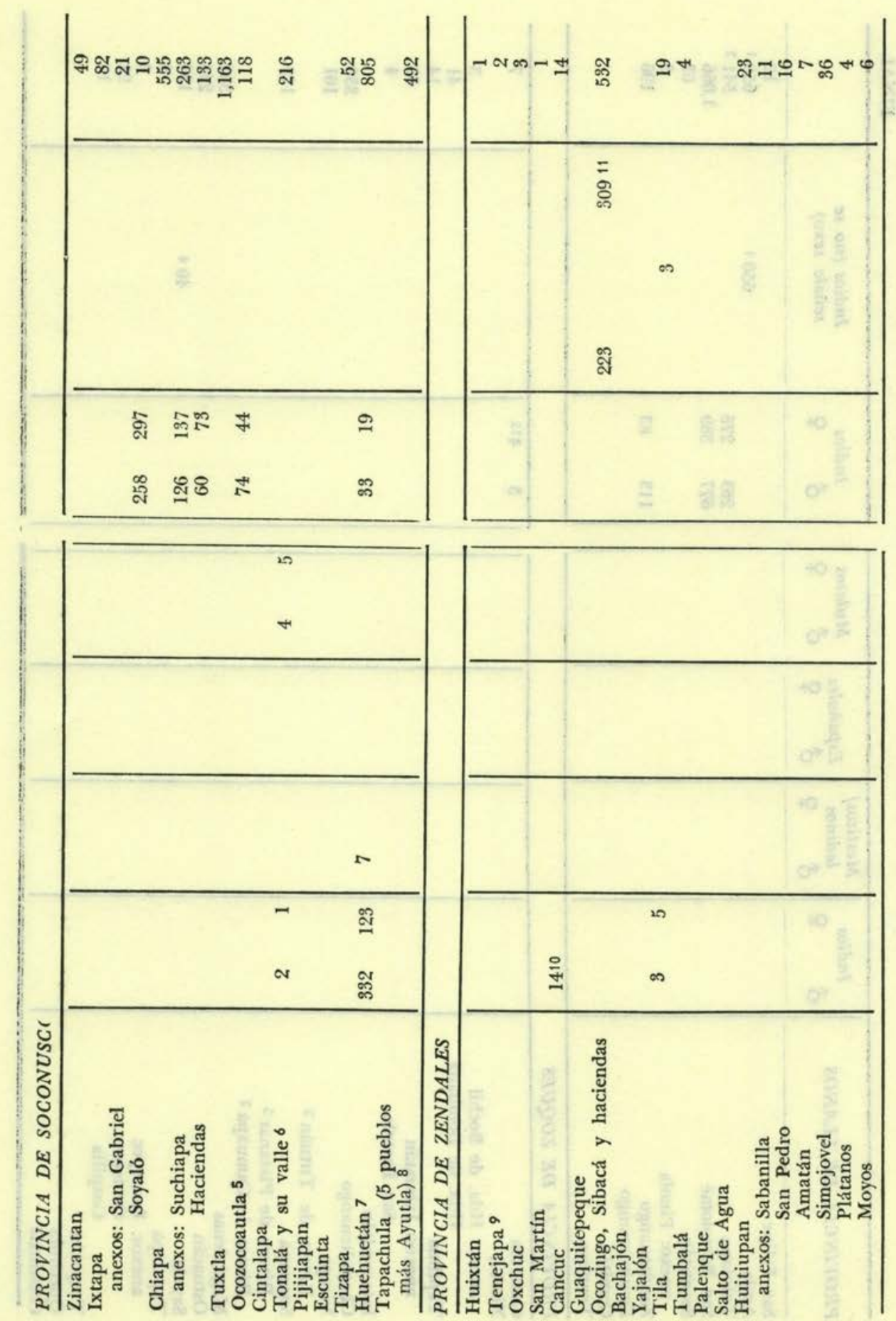

Estudios de Cultura Maya. Vol. XVII, 1988

Instituto de Investigaciones Filológicas/

Centro de Estudios Mayas, UNAM 


\section{Notas al cuadro}

“Distribución por poblado, sexo y calidades del padecimiento...".

1650 afectos de "tiña blanca, negra y morada", sin detallar. Población total: 700 hbs.

2 Incluye 263 indios y 278 indias, afectados de tiña blanca, negra y encarnada, sin detallar.

3 Todos están contagiados. En Tutuán predominan la tiña blanca y la negra, en Platanar y Camuapa, la pinta y la negra.

4 Se especifica que se trata de laborios.

5 Tiña blanca: 39 hombres y 31 mujeres; tiña encarnada: 2 hombres; tiña negra 33 hombres y 13 mujeres.

6 La mixta es "tricolor".

7 Afectados 805 . Población total: 987.

8 La mixta es blanca y negra.

9 Originarios de Totolapa y San Lucas.

10 Sin especificar sexo, afectados de jiote.

11 Tiña blanca: 523, encarnada: 3, negra: 6. Españoles: 2, indios: 519, ladinos: 11.

12 Un matrimonio de Chiapa y otro de San Lucas, sólo 3 son nativos de Chamula.

б : hombres.

우: mujeres. 


\section{-Etiología}

La primera mención a la etiología popularmente invocada para explicar el padecimiento consta en el edicto del obispo, quien tras solicitar a los curas iniciaran sus pesquisas entre los fieles, les encarga "les disuadan la falsa opinión que hemos oído en Chiapa [de Indios] de ser regalo del glorioso patriarca Santo Domingo, patrón de aquel pueblo, su asquerosa enfermedad", lo que nos hace pensar en una alusión a los colores blanco y negro del hábito dominico, que acaso vincularan los feligreses a los cambios de coloración dérmica.

Pero no era el fundador de la Orden de Predicadores el único santo culpable; a decir de los de Totolapa, la responsabilidad había de achacarse a Santa Ifigenia, ${ }^{17}$ quien se cobraba de $\tan$ colorida manera la burla que le habian hecho los habitantes de Chiapa el año de 1772 , mismo en que la zona sufriera -otra sacra represalia- una plaga de chapulín.

Con excepción de la anterior, ninguno de los curas consignó las creencias populares al respecto; casi todos los que se refirieron a aspectos etiológicos - que no fueron muchos- virtieron en el informe sus propias elucubraciones, varias de ellas curiosamente próximas a la realidad, al menos en lo relativo a la cercanía entre la sífilis y el mal en cuestión. Así, el cura de Cancuc apuntaría: "siempre me ha parecido ser la tiña un efecto procedido del gálico, que injerta tantos sintomas cuantas son las disposiciones del sujeto, de los climas o de los alimentos".

El de Tonalá sería más contundente al aseverar, "la tiña no es otra cosa que gálico, pero bien se deja ver la diferencia que hay de uno a otro... [pues si bien en Tabasco abunda el primero], en aquella provincia no se conocieron las manchas de tiña hasta que los chiapanecas fueron a ella".

El presbítero de Totolapa, aun en detrimento de la capacidad que adjudicaban sus ovejas a Santa Ifigenia como generadora de venganzas dermatológicas, se alínea con los anteriores: "es visto que [el mal] proviene del gálico". Más hipocrático, el de Soyatitán lo achacaría a la "grosura de humor y putrefacción de la sangre", como lo demostraba el hecho de no padecerla necesariamente ambos cónyuges.

La opinión de don Manuel Ruiz, cura de Ocosingo, Sibacá y

17 No ha sido posible encontrar algún dato hagiográfico que permita entender el por qué de la asociación; ¿acaso por el hábito de la santa? 
sus haciendas, no deja de llamar la atención por lo que hay en ella de próximo a la realidad cuando considera a las hoy conocidas por lesiones iniciales y tardías como originadas en un mismo proceso; ${ }^{18}$ así, tras señalar que en su administración son mucho más comunes los jiotes, que levantan mucha escama, agrega "pero como ésta es tan contagiosa como la otra [especie], y me parece provenga de la misma causa, la reduzco y pongo en la planilla por la tiña blanca". Por desgracia, no menciona cuál era el origen que ambas "especies" de tiña compartían.

$\mathrm{El}$ juicio más extenso y razonado en éste como en otros rubros es el de don Manuel Mariano Chacón y Becerra, cura beneficiado de Ixtapa, San Gabriel (hoy El Palmar) y Soyaló, quien yendo en contra de la opinión común (ser "morbo gálico"), invoca una ectoparasitosis como la etiología "más adaptable y conforme a razón", precisando que se trata de

un animalillo muy sutil que, introduciéndose intercutáneamente, mina el cutis -a la manera que el animalillo de la sarna- ${ }^{19}$ por cuyo motivo se contagian más presto los que residen en tierra caliente, por tener los poros del cuerpo más dispuestos a la introducción de dicho animalillo, percibiéndolo de los ya contagiados.

Es tan evidente este concepto, como que aseveran los que la padecen [la enfermedad] que como viéndose dichos animalillos con los calores. del Sol, les causa una extraña comenzón hasta amortiguarse aquella parte dañada con el rigor del Sol.

Contra una mera "infección intercutánea" se pronunciaría el cura de Cancuc, alegando que el proceso afectaba "la masa de la sangre", pues había observado en un tiñoso con una gran herida que: "a la primera cicatrización salió aquel primer cutis [epidermis] manchado inmediatamente, sin que precediese tiempo a la propagación de la tiña en aquella parte".

\section{-Signos y síntomas}

Los textos que se detengan en señalar las manifestaciones clinicas del padecimiento son los menos, pero ello no es de extrañar si tomamos en cuenta que las lesiones cutáneas son prácticamente las únicas perceptibles, ${ }^{20}$ y que éstas constaban en los datos censales que cada cura enviaba.

18 Saúl (op. cit.:194) señala que las píntides "fueron conocidas por los enfermos mucho antes que los dermatológicos mexicanos las identificaran".

19 Sarcoptes scabiei.

20 Las alteraciones a nivel de faneras (decoloración del cabello, espesamien- 
Tenemos pues sólo cuatro testimonios al respecto. El primero de ellos, otra vez, es el del propio obispo, quien al iniciar su edicto nos proporciona una descripción que habla más de los ojos e impresiones del sano que de la piel del enfermo, a la vez que nos ilustra sobre la dudosa fama que, gracias a la enfermedad, habían conquistado sus polícromos fieles:

Antes de conocer la provincia de Chiapa, habiamos oído a cuantos han transitado por ella el horror y asco que les causaba la vista de sus habitantes, por tener los cuerpos afeados con unas manchas de diversos colores cuyo espectáculo espanta generalmente aun a aquellos mismos que están acostumbrados a verlo.

Confesamos haber sentido una conmoción igual en el espíritu cuando observamos con nuestros propios ojos tan extraordinaria fealdad, y nos la aumentaba lo insoportable de su hediondez y la aspereza de su cutis, que cual una lija nos raya el dedo al ponerles sobre la frente el sagrado crisma. ${ }^{21}$

El cura de Ocozocoautla señalaría que en su jurisdicción "las manchas más comunes son las blancas, con alguna mixtura negra", y se anticiparía a los dermatólogos mexicanos al notar que la variedad "encarnada" [el eritema predominante] "no se encuentra entre los indios" sino sólo en los ladinos, presumiblemente de piel más clara. El de Totolapa, por su parte, menciona que los enfermos aseguraban "que no les duele; que trabajan, corren y duermen" sin ningún problema, aunque agrega que durante su estadía en Soconusco pudo ver cómo a los afectados por jiotes ("otra enfermedad más pestífera y "escocedora"), "se les levanta el pellejo como escamas; están en un continuo rascar..." que sólo se les alivia por corto rato metiéndose al río, restregándose con piedras [टpomes?] hasta ensangrentarse y repitiendo luego el baño. El de Ixtapa, como ya vimos, hablaba de prurito exacerbado por la exposición al Sol.

Al bachiller Mariano Nicolás de Robles, cura de Tonalá, debemos la descripción más completa del padecimiento tanto en sus lesiones iniciales y tardías, como en la variedad de pigmentaciones, lo que no es de extrañar si tomamos en cuenta que el pueblo

to $\mathrm{y}$ estrías longitudinales en las uñas) y la poliadenopatía que puede aparecer en la fase primaria (Saúl, op. cit.: 195), se antojan difícilmente perceptibles para quien no sea médico. Ni qué decir pues si el observador vivía en 1798.

21 De esta mención se deriva acaso la hipótesis de Orozco y Berra, ya señalada, sobre el temor de los prelados al contagio, 
de Tonalá, además de albergar indios y españoles, era un asiento. importante de mulatos. La presencia de lesiones secundarias, y probables cuadros mixtos [dermatitis por contacto], parece poder atribuirse al trabajo en los beneficios del xiquilite o añil.

Las especies de tiña que se conocen en este pueblo son: blanca, negra y colorada. Hay.... algunos individuos que tienen de todas tres. especies; la hediondez de éstos es insoportable, tienen el cutis más. áspero que los demás [y] su figura es la más espantosa; se [a]semejan a las pieles de los tigres. Tienen un ardor intolerable, especialmente en los días en que entran a las canoas a batir los añiles, porque hacen este ejercicio desnudos, y llegan a tal extremo que se restriegan sobre la tierra lo mismo que las bestias. Van distinguidos [en el lis. tado]... con el nombre de tres colores; en este pueblo llaman a estos. overos. 22

Hay otra especie muy diferente, estos tienen unas manchas que hacen un medio [matiz] entre el azul y el verde, con unas rajaduras que les. forma una especie de escama; por ellas no echan humor alguno, y se distinguen con el nombre de jiotes.

\section{-Diagnóstico diferencial}

Si bien en la actualidad sabemos que las píntides no son más. que lesiones iniciales del Pinto, y que el agente causal emparenta este padecimiento con el pian y la sífilis, nada de ello podía pasar por la mente de nuestros curas; aunque como hemos visto. no dejaron de aventurar elucubraciones brillantes sobre aspectos. etiológicos, y otro tanto harían al intentar diferenciar lo que consideraban cuatro enfermedades: lepra, jiotes, morbo gálico y tiña.

Para el obispo, como ya señalamos, la patología que afectaba sus feligreses, era impropiamente llamada tiña, y si bien tenía "varios nombres en varias partes", a él se le antojaba una "especie rara de lepra”. La misma impresión había causado el padecimiento en el cura de Cancuc, al bautizar a un pequeño, pero "a los quince días se le cayó aquella apariencia y quedó todo el cuerpecito cubierto de esta tiña que llamamos jiote".

Al obispo no le escapaba que había "diversas especies... que se distinguen por sus colores", de ahí que insistiera en la necesidad de registrarlas en los informes, destacando cuál era la más. común en cada área.

De que los jiotes se consideraban especie diversa de la "tiña"

22 Overos: término que se aplica a los animales, sobre todo a los caballos, que tienen mezcla de pelos rojos y blancos, semejando al melocotón (Moliner, 1984, II:595). 
son buena muestra las declaraciones de los curas de Tonalá y Ocosingo a que antes nos referimos; para el de Totolapa éstos eran, en cambio, "otra enfermedad", pero los tres coincidieron en puntualizar que la principal característica de éstos era su naturaleza "escamosa", característica en efecto de las píntides (Saúl, op. cit.: 194) .

Para el presbítero de Tonalá la tiña no era sino mal gálico, aunque agrega que "bien se deja ver la diferencia que hay de uno a otro"; curiosa puntualización que no se molesta en explicar. El sustentante de la opinión contraria es el cura de Ixtapa, quien, como de costumbre, se explaya en explicaciones, señalando para sustentar su hipótesis de una etiología ectoparasitaria, que

si fuera morbo gálico (como muchos piensan) $u$ otro accidente que contaminara a la sangre, lo primero, se contagiarian más fácilmente y hubiera más enfermos en tierra fría que en la caliente, pues en ésta se expele más fácilmente el mal humor por el sudor que en aquella. Lo segundo, que la misma experiencia enseña que habiendo muchos casados, siendo un consorte limpio y el otro dañado, era natural que por medio de cohabitación se infestaran ambos, y no verificándose esto, sino también nacer la prole y criarse limpia de este contagio, aun con la frecuente comunicación y trato regular (a no ser que la naturaleza de alguno de estos esté dispuesta para percibir dichos animalillos), luego se infiere ser el [causante el] referido ani. malillo, que no contamina más de la superficie del cutis, y la prueba es clara.

\section{-Terapéutica}

Si el apartado relativo a epidemiología se revela como el más rico en datos, el que da cuenta de los tratamientos es sin lugar a dudas aquél que con mayor detalle nos habla del ingenio desplegado por algunos pobladores para librarse de la enfermedad, casi siempre con escasos resultados, lo que desanimó a algunos de procurar su curación; así, a decir del cura de Ocozocoautla, nadie en ese pueblo se había curado, "ni menos han hecho la diligencia porque se ignora cuál sea el remedio de esta enfermedad", y otro tanto ocurría en Tapalapa, Acala, Huixtán, Oxchuc, San Martín, Chapultenango, Sunuapa, Nicapa y Zinacantan. Los de Tila, Ocosingo y Tizapa, en cambio, sí habían intentado diversos métodos, pero sin encontrar "remedio que les aproveche".

Socoltenango, por su parte, había sido testigo de la curación de algunos, "aunque muy pocos", pero la terapéutica sólo era efectiva si se instauraba al apenas mostrarse las primeras lesiones. 
Deberían entonces tomarse los cogoyos de la yerba llamada barba de león, se amortajaban bien y se restregaban sobre la mancha -previamente "rascada" - "hasta perderse o aniquilarse ésta".

También Ixtapa se inclinó por la herbolaria, en este caso empleando el "apio de la tierra" en forma de emplastos; la mancha se levantaba en forma de ámpula, lista para cortarse. ${ }^{23}$ Según Chacón y Becerra el medicamento estaba muy experimentado y sólo su agresividad ("mucho más en partes delicadas") impedía que su uso se popularizara.

El cura de Soyatitán mencionó haber presenciado en Comitán la curación de don Ramón Velasco, "cubierto todo de tiña prieta", gracias a la mezcla de agentes sobrenaturales y naturales; los primeros representados por una promesa de visitar a la Virgen de Candelaria de Chiantla [Cuchumatanes, Guatemala] y los segundos, más modestos, en forma de

aquel fermento que queda del aguardiente después de estilado el espiritu, y con unas pepitas de higuería [higuerilla] machacadas y fermentadas con la viscosidad que acostumbran dejar las chiceras o aguardienteras, se bañaba y se echaba a sudar. $Y$ después se volvía a bañar con agua natural, y con esto quedó enteramente limpio, y lo está.

Los remedios compuestos parecen haber sido los más socorridos; alguno reunía productos animales y vegetales en su factura, pero la mayor parte se inclinaba por conjuntar los primeros con el mercurio o azogue, cuyo uso nos habla de nuevo de la cercanía observada entre la "tiña de Chiapa" y la sífilis. ${ }^{24}$

Caldo de zopilote o posol a los que se agregaba "cinco granos de chilillo con el que matan los coyotes" era el curioso tratamiento empleado en Soconusco para curar las píntides. Tras ingerirlo

${ }^{23}$ El hecho de que levantándose la piel afectada desapareciera la enfermedad, fue por supuesto empleado por el presbitero para corroborar su aseveración de que se trataba de un "accidente puramente intercutáneo y no de putrefacción de sangre".

24 En este sentido es ilustrativa la larga digresión de Ramón de Torres, quien tras hablar de los tratamientos empleados en Soconusco-que combinaban baños con otras terapias- agrega que vio en La Habana dar "unciones a los gálicos con los baños... Asimismo, el uso de la Panacea o mercurio dulce, que lo toman como pildoras de confetes, y conocí a muchos que las traían en las bolsas y las tomaban sin recelo; con el corrosivo se despreció, porque los que lo toma[ba]n a los tres años morían y se les encontraba la osamenta extraña. De modo que se ha hecho tan doméstico el uso del mercurio que no le temen, porque veían los espectáculos tan monstruosos con que en su aplicación bárbara se empeñaban los médicos". 
el paciente experimentaba una fuerte calentura; arropado, sudaba en abundancia; se bañaba al día siguiente y adiós los jiotes según el presbítero, quien no olvida mencionar que parte imprescindible de su efectividad era que el enfermo no supiera lo que estaba tomando.

El azogue parece haber sido el favorito entre los medicamentos de la época; se empleaba en Totolapa, Ixtacomitán, San Bartolomé, Tuxtla, Tonalá, Tapachula y Cancuc. No sabemos cómo se empleaba en el primero de estos pueblos, pero su cura nos menciona que en Ixtacomitán vio que lo mezclaron con sebo en proporción 1:2, untándose sobre las manchas al ir a dormir y bañándose al día siguiente. "En tres unturas quedaban buenos, pero siempre la tiña blanca quedaba. Sin más dieta que el modo común de vivir de ellos; que, a tener [en esto] método, todos quedarían buenos".

El cura de San Bartolomé, don Joseph Patricio Chinchilla, coincidió en el remedio, precisando que el sebo debía de ser de res, frito y bien colado, agregándose a una onza media de azogue. El compuesto, tibio, se aplicaría una vez en el día y otra por la noche, "sin ningún otro régimen". El tratamiento, empero, únicamente era efectivo si se empleaba al apenas comenzar a registrarse las manchas.

En Cancuc "era público" que tal compuesto, "sin más preparación que baños intermedios a las unturas", había sanado a algunos, lo que el cura atribuye a la acción del mercurio que, "introduciéndose por los poros del uerpo, penetra las venas, arterias, nervios, tendones [y] huesos, hasta los más sólidos y duros".

Mientras que el presbítero de Socoltenango mencionó haber oído que en Tuxtla "una tal Antonia Palacios", había curado a ciertos enfermos "con una untura que hace con sebo de riñonada y azogue", el doctrinero del mismo pueblo envió una detallada receta con la que, apunta, "todos los que con ella se han curado han sanado".

Primero se hervía y colaba el sebo, agregando a cuatro onzas de sebo limpio una de azogue; bien revueltos se ponía la mezcla "todos los días al sol y al sereno, y todos los días se bate hasta que el sebo quede azulejo y bien unido con el azogue". Luego se extendía la mezcla sobre las manchas antes de cenar, cuidando que penetrara bien. Al día siguiente, "antes que salga el Sol" y en ayunas, el paciente debía bañarse en el río "restregándose bien con un estropajo". 
Durante los nueve días que duraba el tratamiento, todos los alimentos habían de comerse asados y el enfermo no podía salir al sereno.

La receta daba cuenta incluso de efectos colaterales y su remedio, en una nota: "si acaso se les hinchare la boca y babearen en este lance, se les da leche caliente hasta que pare la baba".

El cura de Tonalá registraba el mismo remedio (efectivo en Tehuantepec y Tuxtla) precisando que tras el baño debería efectuarse cambio de ropa y que la "dieta" a seguir no era tan "penosa" que les impidiera el paseo; bastaba con que los afectados se acostaran temprano y dejaran la cama tarde, ya de día. Debía recordarse, empero, que algunas "especies de tiña" se resistian más que otras, pero a la larga este "dilatado... medicamento" era siempre efectivo, no como los usados antes: "remedios más... para aumentar su tormento que para proporcionarles algún alivio", que las gentes "decidiosas e ignorantes" emplearon "por más de un siglo".

En Tapachula el tratamiento mercurio-sebo registraba dos pequeñas adiciones: una purga suave previa a la unción del compuesto, y el agregar a éste una "corta cantidad de Solimán".

El Solimán, un corrosivo obtenido por sublimación de cloro y mercurio que se empleó como desinfectante y cosmético, estaba también presente en el arsenal terapéutico de los soyatitecos contra el Pinto, pero ahí se mezclaba con aceite o con jabón y cal. El remedio era efectivo en las manchas pequeñas, mas se dejaba entender, según el cura, que esto valía para los poseedores de "humor delgado, pero en aquellos que tienen el humor grueso y sucio... [cuando] les sale una mancha, al siguiente día salen tantas que ya no se puede verificar curación".

El cura de Chiapa, el pueblo más afectado, fue el único que logró recopilar información sobre terapéuticas diversas según el estadio en que se hallase la enfermedad: ungüento de Solimán sólo en el primer caso ("por su desmedida actividad") y "el magistral" [¿sebo y azogue?] para quienes tenían infestado todo el cuerpo. Sin embargo, agrega, "de ninguno de ellos salgo fiador, ni menos aconsejo que se practiquen; los relato en la misma forma en que los he recibido, sin sondear el valor que en sí contengan. Los facultativos podrán anatomizarlos y medirlos en su propio peso". 


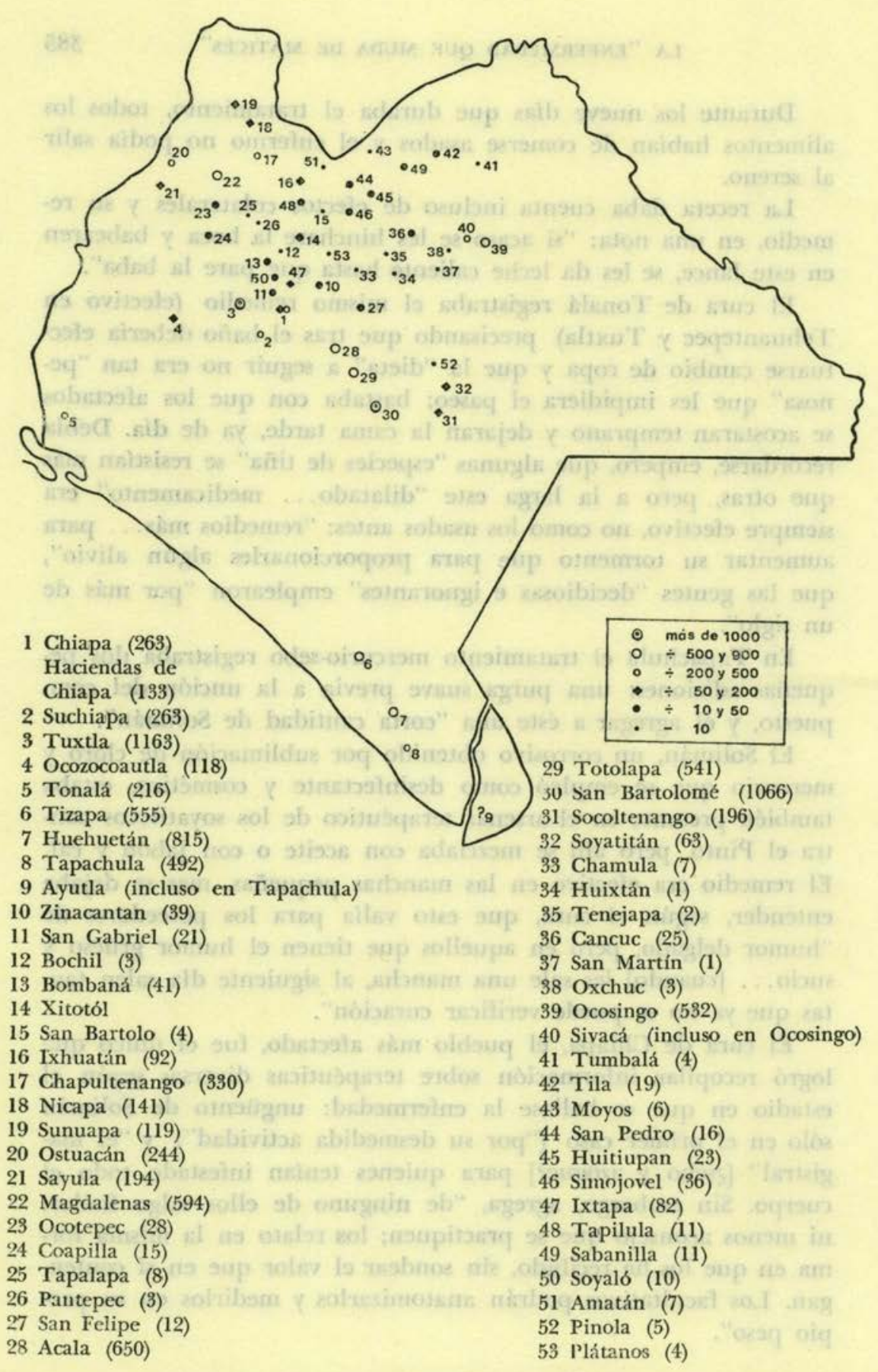

Mapa 3. Densidad de población (1778) y casos de "tiña" reportados en 1798 (Cf. apéndice). 


\section{-Recapitulación}

Varias son las consideraciones de interés que se desprenden del material recopilado por los curas; acaso la primera de ellas sea la heterogeneidad de sus opiniones, explicable tanto por la diversa formación como por la diferente capacidad de observación que tenían, pues, como mencionábamos en un inicio, mientras que algunos de ellos se limitaron a registrar opiniones y conocimientos populares, otros aventuraron hipótesis que en ciertos casos no dejan de ser brillantes.

Acaso las consideraciones epidemiológicas y etiológicas sean las que muestran un mayor rango de diversidad. Vemos así que los presupuestos orígenes del mal en cuestión invocan desde fenómenos sobrenaturales y cambios humorales, hasta un parentesco con la sífilis, en lo cual los testimonios no andaban muy errados. Otros datos de interés en este rubro son la afirmación del cura de Ocosingo, que postulaba un origen común jiotes-Mal del Pinto, en lo cual acertó; la opinión del presbítero de Ixtapa de que la causa primaria era una ectoparasitosis (recordemos que aún no se desechaba una posible transmisión por insectos), la relación de la enfermedad con los climas cálidos, en la que varios insistieron, y el señalamiento de que no existía transmisión sexual ni placentaria, que es una constante en los testimonios.

Dato de gran interés es el proporcionado por el cura de Soyatitán de que durante dos epidemias de viruela los enfermos de pinto se vieron libres de manchas, para recuperarlas una vez que la epidemia cesó. Por desgracia no hemos encontrado en ningún reporte o estudio contemporáneo mención alguna sobre interferencias inmunológicas en ambos cuadros, o del pinto con otras enfermedades eruptivas, que avalara la observación de don Vicente Ramón de Rivera.

Si bien la mayoría de los reportes señalaba la relación del pinto con la sífilis (aunque invocando motivos diversos y en buena parte infundados), el vínculo que el primero mostraba con los jiotes fue más controvertido; así, para el cura de Totolapa eran dos enfermedades distintas, para el de Tonalá eran dos "especies" de una misma, y para el de Ocosingo se trataba de un mismo padecimiento, originado por idéntica causa.

El aspecto clínico, como señalábamos, se prestó a pocas especulaciones. Los datos más interesantes serían el señalado por el cura de Ocozocoautla acerca de que la variedad donde predomina 
el eritema sólo afectaba a los individuos de piel más clara, y la presencia de cuadros mixtos allí donde se trabajaba el añil (Tonalá), lo que acaso explique el prurito reportado en esta área y la de Soconusco - donde también se explotaba el xiquilite- pero que de ninguna manera explica la comezón exacerbada por el Sol de la que habla el cura de Ixtapa. En todo caso, ningún autor moderno reporta este síntoma dentro del cuadro clínico de la enfermedad.

Hemos señalado ya la forma y tiempos en que propagó la enfermedad ( $C f$. mapa 2 ) y el papel que en ello jugaron el comercio y la emigración masiva de los habitantes del pueblo de Chiapa, y su entorno, durante las epidemias de langosta que afectaron el área. Claro resulta también en los cuadros que el contagio fue más acusado en las poblaciones asentadas en tierra caliente, como es característico de la enfermedad. Así vemos, por mencionar algunos ejemplos, que la máxima concentración de enfermos ocurre en Tuxtla (1163), San Bartolomé (1066) Huehuetan (815), Acala (650), Magdalenas (594), Tizapa (555), Totolapa (541) y Ocosingo (532), mientras que el total de individuos que presentaban lesiones en los pueblos de la región conocida como Los Altos, apenas llegaba a 58 según los reportes de los curas.

No poseemos por desgracia datos exactos sobre la población total de la zona en la época, y mucho menos sobre sus caracteristicas raciales, pero sabemos que durante toda la época colonial y buena parte de la independiente, la mayoría fue abrumadoramente indigena. Así, para 1778 se calculaban apenas en 7480 españoles y mestizos los existentes en Chiapas, mientras que cincuenta y tres años antes la población indigena, brutalmente diezmada, alcanzaba los 50 mil individuos (MacLeod, 1985:55-56). Tampoco contamos con datos cuantitativos para el área de Soconusco, aunque se sabe que para 1778 los pobladores no indígenas superaban en número a los indios (ibid.).

$\mathrm{Si}$ bien lo anterior parecería explicar el predominio de la variedad de "tiña negra o prieta" en la región, no deja de causar extrañeza el alto número de enfermos indios aquejados por la variedad "encarnada", es decir la eritematosa, que tan sólo en Tuxtla llegaban a 237 sobre un total de 1163 (esto es, un 20.27\%), Empero, no debe pasarse por alto que la clasificación por "colores" o "matices", hecha además por un lego en medicina, es bastante arbitraria, aunque -si hemos de confiar en el ojo clínico del cura- era en el pueblo de Tuxtla donde se observaba mayor 
diversidad en cuanto a los cambios cromáticos: al $22.35 \%$ total de variedad encarnada (incluyendo indios, mulatos, mestizos y españoles), se suman un $46.34 \%$ de negra y un $31.29 \%$ de blanca; no se reportaron jiotes, aunque éstos pudieron haber sido incluidos (como en el caso de Ocosingo), dentro de la variedad 'blanca'. Dada su intima vecindad geográfica, los datos de Acala y Chiapa pudieran corroborar o invalidar lo referido para Tuxtla, pero lamentablemente los curas de estos pueblos no reportaron datos específicos para las variedades.

Ahora bien, si desglosamos los datos totales según las "calidades" de los enfermos, como las llamara el obispo, obtenemos el siguiente cuadro:

Mestizos/

\begin{tabular}{|c|c|c|c|c|c|c|}
\hline Negra o prieta & 2154 & 112 & 91 & 4 & 2361 & 26.25 \\
\hline Blanca & 1006 & 101 & 18 & 12 & 1137 & 12.67 \\
\hline Encarnada & 459 & 31 & 17 & 6 & 513 & 5.73 \\
\hline Pinta o Mixta & 269 & 62 & 6 9 & 3 & 343 & 3.89 \\
\hline Escamosa o jiote & 480 & 7 & 9 & - & 496 & 5.53 \\
\hline Sin especificar & 4106 & - & - & - & 4106 & 45.84 \\
\hline Total & 8474 & 313 & 144 & 25 & 8956 & Woxity gly \\
\hline$\%$ & 94.6 & 3.5 & 1.63 & .20 & 14 & enatiat 1 . \\
\hline
\end{tabular}

Es necesario hacer notar que el cuadro anterior no incluye a todos los enfermos; como se habrá notado en la sección de epidemiología algunos curas se limitaron a reportar el total de feligreses afectados sin especificar de qué variedad se trataba, aunque mencionando a qué grupo étnico pertenecían (ej.: el de Totolapa); otros hicieron lo inverso, es decir registraron la variedad cromática pero no el grupo étnico (ej.: el de Ocozocoautla) y hubo quien reportó los totales globales sin especificar distinción alguna (ej.: el de Chiapa). Caso particular es el del cura de Ocosingo, quien reportó cuántos enfermos de cada variedad había y cuántos de cada grupo étnico padecían de pinto, pero sin cruzar los datos. No debe olvidarse, empero, que en los dos primeros casos (Totolapa, Ocozocoautla) la población era por entonces mayoritaria- 
mente indígena, y que el cura de Chiapa señaló que los 555 habitantes que presentaban la enfermedad eran todos indios. De los 532 enfermos de Ocosingo, 519 eran indios, reportándose apenas 11 ladinos y 2 españoles.

En este sentido, aunque sin mucha precisión, los reportes de los curas nos permiten conformar, al menos cualitativamente, la distribución de los grupos étnicos en el área: Los Altos y Zoques eran asiento exclusivo de indígenas, mientras que en el Soconusco se presentaban todas las "calidades".

Si bien no encontramos en los reportes actuales datos que hablen sobre una mayor incidencia del padecimiento en alguno de los dos sexos, nuestros datos muestran claramente su predominio en la población masculina (excepto en el grupo mestizo), lo que podría corresponder con la mayor movilidad espacial de los hombres, a cuyo cargo han corrido tradicionalmente no sólo las actividades comerciales, sino incluso el desempeño de labores agrícolas en tierras alejadas de sus núcleos poblacionales de origen.

\section{\begin{tabular}{l|l|l|} 
Etnia/sexo & Tariedades & Total $\%$
\end{tabular}}

\begin{tabular}{|c|c|c|c|c|c|c|c|c|}
\hline ves: & Negra & Blanca & Encarnade & Mixta & Escamosa & $\left|\begin{array}{ll}\text { Sin } & \text { espe. } \\
\text { pecificar }\end{array}\right|$ & wing & $\sin i$ \\
\hline Indios & 1319 & 509 & 247 & 164 & 337 & 1820 & 4396 & 53.03 \\
\hline Indias & 835 & 497 & 212 & 105 & 129 & 1633 & 3411 & 41.15 \\
\hline Mestizos & 81 & 44 & 16 & 12 & 7 & - & 160 & 1.93 \\
\hline Mestizas & 31 & 57 & 15 & 50 & $8-$ & - & 153 & 1.84 \\
\hline Mulatos & 76 & 10 & 12 & 7 & 4 & - & 109 & 1.31 \\
\hline Múlatas & 9715 & 8 & $\cos 5$ & 2 & 2810 & - & 35 & 0.42 \\
\hline Españoles & 4 & 6 & 2 & 3 & - & - & 15 & 0.18 \\
\hline Españolas & $\ln \pi$ & 6 & $\sin 4$ & 4 & -4 & $-n$ & 10 & 0.12 \\
\hline Total & $2361^{\circ}$ & 1137 & 513 & 343 & 482 & 3453 & 8289 * & \\
\hline
\end{tabular}

- No se incluyen los 650 enfermos indios de Alcala, por no constar su sexo ni la variedad cromática del padecimiento, ni tampoco los 14 indios afectados en Cancuc, cuyo sexo no se reportó.

Por último, si cruzamos las variables variedad cromática y 10 . calización geográfica en un cuadro, ignorando la distribución caprichosa que marca la cordillera, y ubicando a Zinacantan, San Felipe y Chamula en la zona de Tierras Altas, donde se encuen- 
tran, y a Tuxtla, Ocozocoautla y Cintalapa en la provincia de Zoques, a la que correspondían, y dada su cercancía geográfica y climática agrupamos junto a esta última al priorato de Chiapa y el pueblo de Acala, obtendremos los siguientes resultados:

Area Variedad $\%$ Total Área

\begin{tabular}{|c|c|c|c|c|c|c|c|c|}
\hline & Negra & Blanca & \begin{tabular}{|} 
Encar- \\
nada
\end{tabular} & $\begin{array}{l}\text { Esca- } \\
\text { mosa }\end{array}$ & Mixta & $\begin{array}{l}\text { No espe- } \\
\text { cificada }\end{array}$ & & \\
\hline Zoques-Chiapa & 1466 & 1021 & 461 & - & 121 & 1641 & 4710 & 52.91 \\
\hline Llanos & 67 & - & - & - & 1 & 1803 & 1871 & 21.01 \\
\hline Soconusco & 604 & 182 & 54 & 474 & 219 & 52 & 1585 & 17.86 \\
\hline $\begin{array}{l}\text { Zendales y } \\
\text { Guardianía }\end{array}$ & 172 & 527 & 3 & 22 & & 10 & 734 & 8.22 \\
\hline Total & 2309 & 1730 & 518 & 496 & 341 & 3506 & 8900 & \\
\hline$\%$ variedad & 25.94 & 19.43 & 5.82 & 5.57 & 3.83 & 39.4 & & \\
\hline
\end{tabular}

Poco podemos abundar sobre las diferentes terapéuticas empleadas; baste recordar que en realidad la única que parece haber mostrado cierta efectividad era la que usaba el mercurio. Incluso fue éste el medicamento utilizado por Moziño, cuya acción se redujo apenas a darle el espaldarazo científico a la terapéutica ya empleada por el pueblo. Los otros remedios nos hablan, más que de un criterio racional, de la imaginación popular. En tal sentido, el caldo de zopilote y las promesas a la Virgen de Chiantla, bien pueden colocarse en el mismo rango: la búsqueda ansiosa de los enfermos por librarse, a cualquier costo, de un padecimiento cuya magnitud adquiría ya las proporciones de catástrofe.

Pero no todos reaccionaron de la misma manera; en el extenso informe que el Protomedicato turnara en 1813 al presidente de la Audiencia se anota que los chiapanecas

viven muy sanos, y tan contentos con esta marca... que... es como infamia entre ellos el no tenerla... pues los que no la tienen en la. cara se la ponen artificialmente, usando del achiote, del tizate y del humo para pintársela, y ésta es la mejor gala con que se presentan en sus funciones públicas, que llaman Narzezé. ${ }^{25}$

25 En Nazar ( $o p$. cit.: 37-38. Subrayado en el original). 
Así pues, ante la imposibilidad de deshacerse del estigma, los habitantes de Chiapa no sólo aceptaron vivir con él, sino que incluso llegaron a reivindicarlo como parte de su cotidianeidad, y acaso también, ¿por qué no?, como símbolo de su alteridad.

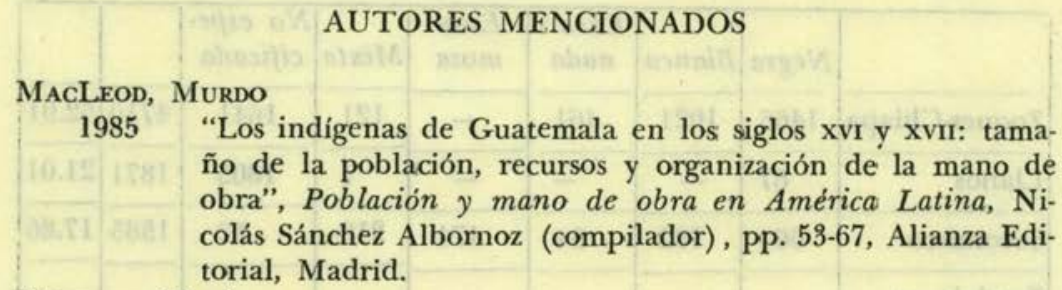

MOLINER, MARÍA

1984 Diccionario de uso del Español, Editorial Gredos, Madrid (Biblioteca Románica Hispánica, V. Diccionarios, 5), 2 vols.

Nazar Cal y Mayor, Alberto

1962 "Mal del Pinto en Chiapas durante los siglos xvir y xix" ICACH, núm. 8, pp. 12-47, Instituto de Ciencias y Artes de Chiapas, Tuxtla Gutiérrez, enero-junio.

Orozco y Berra, Manuel.

1854 Diccionario Universal de Historia y Geografia, t. V, Imprenta de F. Escalante y Compañía, librería de Andrade, México.

Ruz, Mario Humberto

en prensa "El hospital del común de pobres de solemnidad de Comitán", en Chiapas colonial: dos esbozos documentales, Centro de Estudios Mayas, UNAM, México.

Saúl, Amado

1977 Lecciones de Dermatologia, Francisco Méndez Cervantes, Editor, México, Novena edición.

Taracena Arriola, Arturo

1983 La expedición cientifica al Reino de Guatemala, Editorial Universitaria de Guatemala, Guatemala, C. A.

\section{Documentos}

“Año de 1798. El ilustrísimo señor doctor don Fermín Joseph Fuero, del Consejo de su majestad, dignísimo obispo de Chiapa, etcétera, sobre la curación de la especie de lepra vulgarmente nombrada tiña. Secretaría de Gobierno".

AHD, sin clasificación. Cien fojas.

1983 "El obispo de Chiapas, dr. Fermín José de Fuero, combate el mal del Pinto" (1798), Boletín del Archivo General de Chiapas, Año II, núm. 3, pp. 39-54, Tuxtla Gutiérrez, Chiapas, $2^{7}$ edición. 


\section{APÉNDICE}

Población en Chiapas según el censo de 1778; * y vecinos enfermos veinte años más tarde

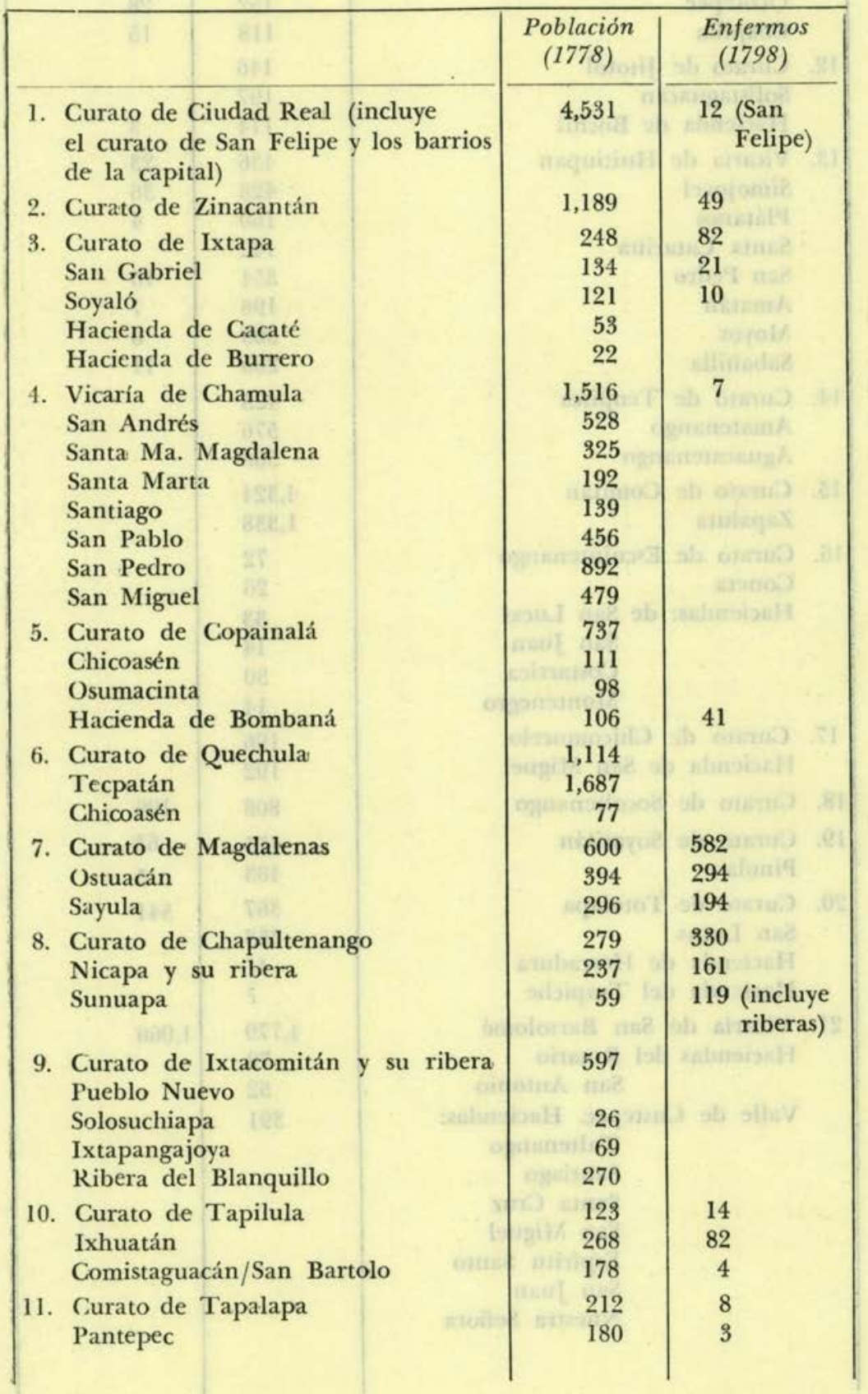




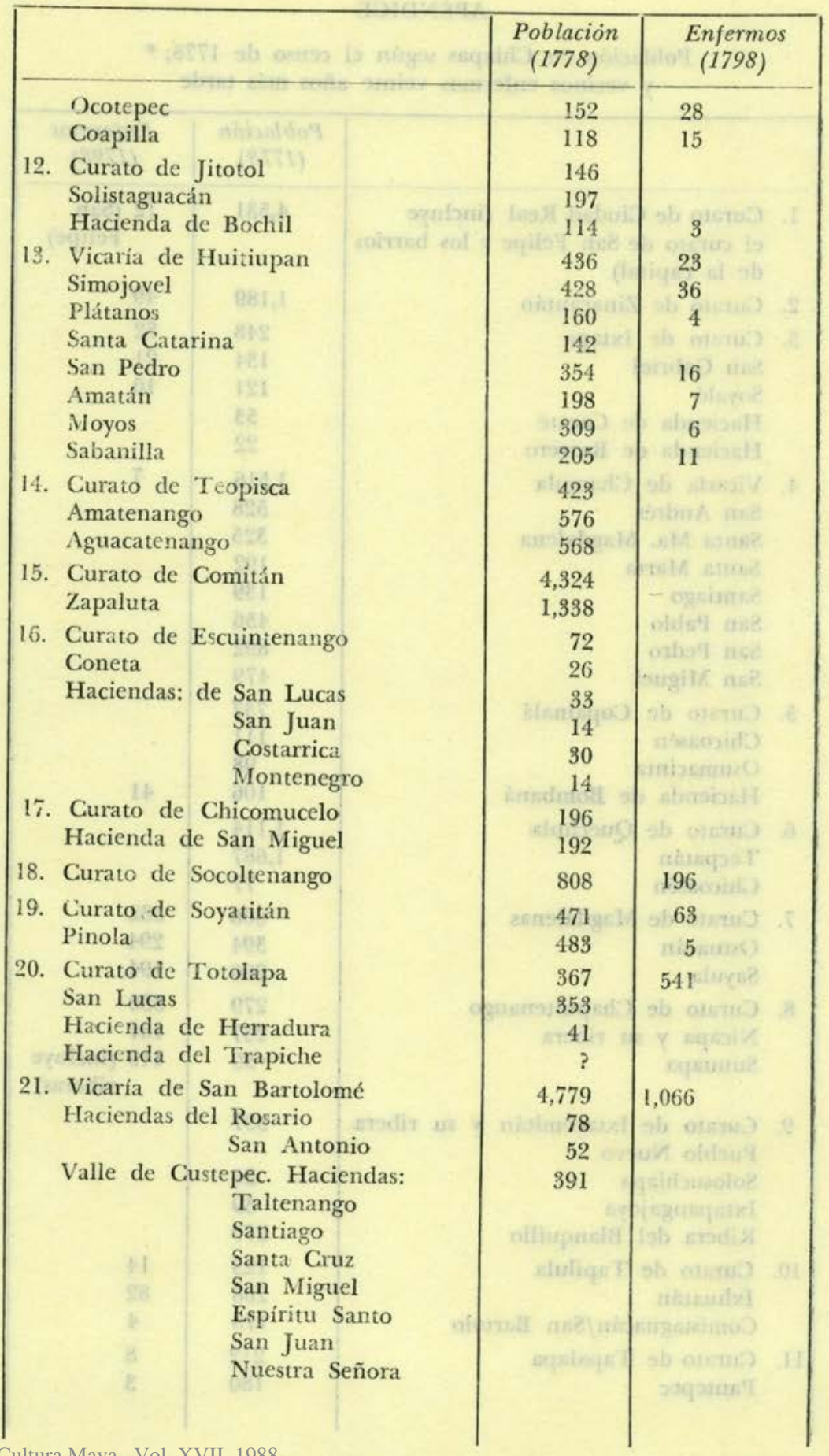




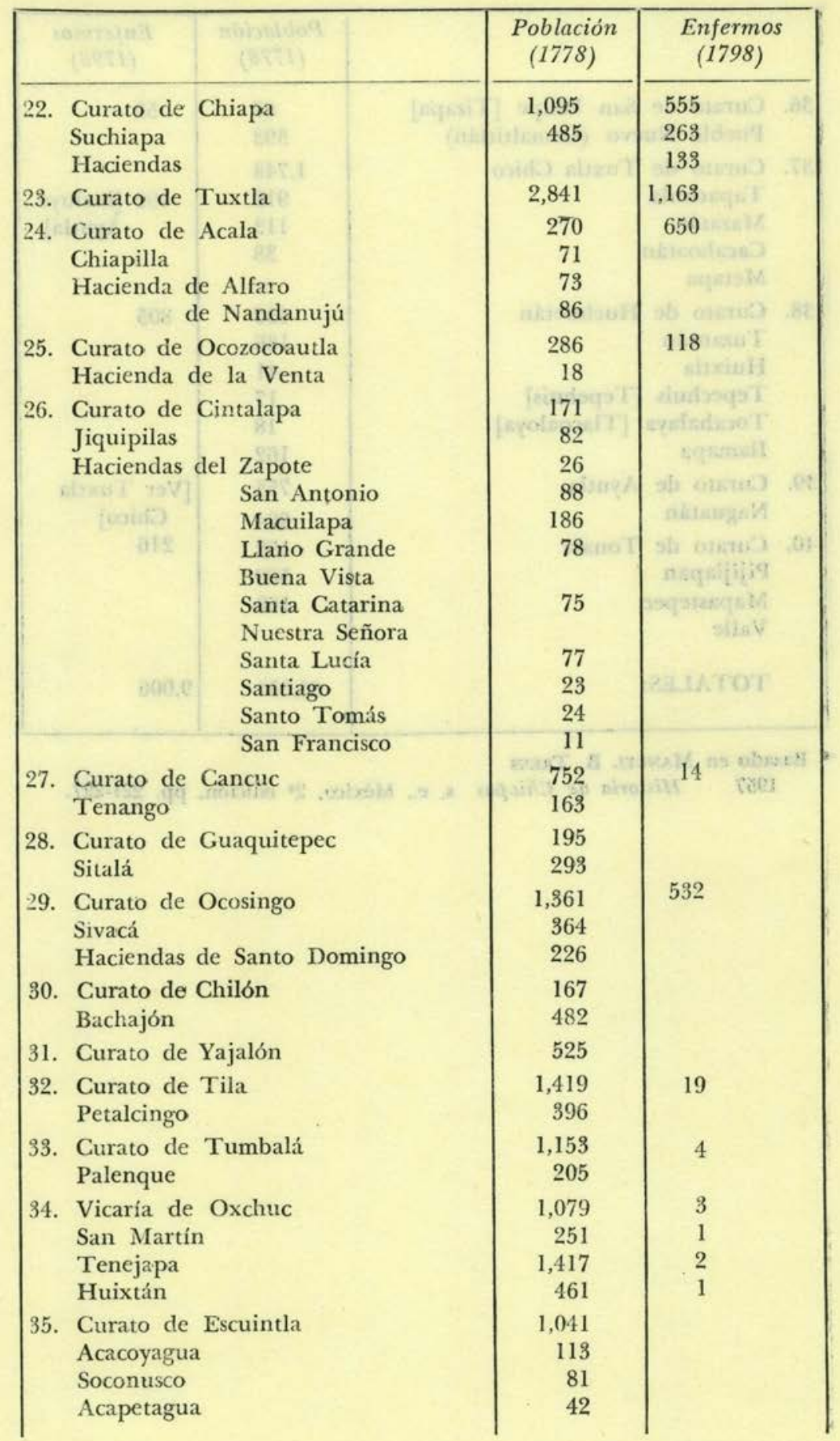




\begin{tabular}{|l|c|c|}
\hline 36. Curato de San Felipe [Tizapa] & $\begin{array}{c}\text { Población } \\
(1778)\end{array}$ & $\begin{array}{c}\text { Enfermos } \\
(1798)\end{array}$ \\
Pueblo Nuevo (Comaltitlán) & 67 & 52 \\
37. Curato de Tuxtla Chico & 393 & \\
Tapachula & 1,748 & \\
Mazatán & 912 & 492 [incluye \\
Cacahoatán & 113 & Ayutla] \\
Metapa & 38 & \\
38. Curato de Huehuetán & - & \\
Tuzantán & 450 & 805 \\
Huixtla & 186 & \\
Tepechuis [Tepehuis] & 41 & \\
Tocahalaya [Tlacoaloya] & 17 & \\
Ilamapa & 18 & \\
Curato de Ayutla & 162 & \\
Naguatán & 753 & [Ver Tuxtla \\
Curato de Tonalá & 924 & Chico] \\
Pijijiapan & 152 & 216 \\
Mapastepec & 509 & \\
Valle & 168 & \\
TOTALES: & & \\
& & \\
\hline
\end{tabular}

Basado en Manuel B. Trens

1957 Historia de Chicpas s. e., México, $2^{4}$ edición, pp. 221-227. 